\title{
Champions of IS Innovations
}

DOI:

10.17705/1CAIS. 04438

\section{Document Version}

Accepted author manuscript

Link to publication record in Manchester Research Explorer

\section{Citation for published version (APA):}

Renken, J., \& Heeks, R. (2019). Champions of IS Innovations. Communications of the Association for Information Systems, 44, 1. [38]. https://doi.org/10.17705/1CAIS.04438

\section{Published in:}

Communications of the Association for Information Systems

\section{Citing this paper}

Please note that where the full-text provided on Manchester Research Explorer is the Author Accepted Manuscript or Proof version this may differ from the final Published version. If citing, it is advised that you check and use the publisher's definitive version.

\section{General rights}

Copyright and moral rights for the publications made accessible in the Research Explorer are retained by the authors and/or other copyright owners and it is a condition of accessing publications that users recognise and abide by the legal requirements associated with these rights.

\section{Takedown policy}

If you believe that this document breaches copyright please refer to the University of Manchester's Takedown Procedures [http://man.ac.uk/04Y6Bo] or contact uml.scholarlycommunications@manchester.ac.uk providing relevant details, so we can investigate your claim.

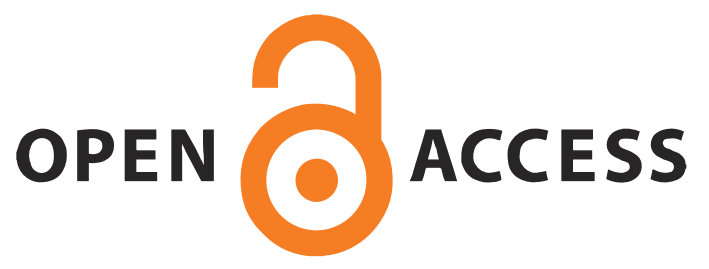




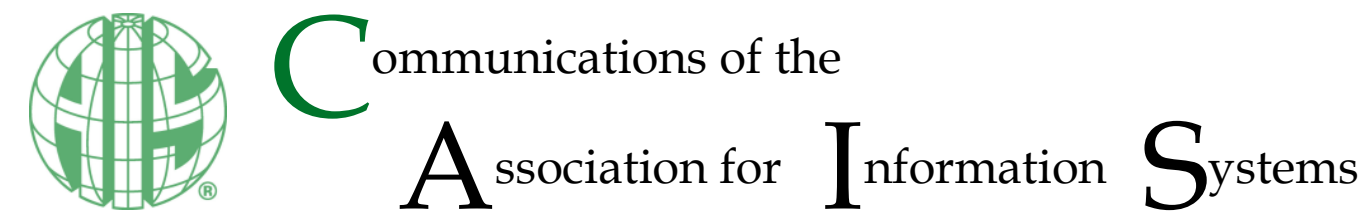

\section{Accepted Manuscript}

\section{Champions of IS Innovations}

\author{
Jaco Renken \\ Centre for Development Informatics, University of \\ Manchester \\ jaco.renken@manchester.ac.uk
}

\author{
Richard Heeks \\ Centre for Development Informatics, University of \\ Manchester \\ richard.heeks@manchester.ac.uk
}

Please cite this article as: Renken, Jaco; Heeks, Richard: Champions of IS Innovations, Communications of the Association for Information Systems (forthcoming), In Press.

This is a PDF file of an unedited manuscript that has been accepted for publication in the Communications of the Association for Information Systems. We are providing this early version of the manuscript to allow for expedited dissemination to interested readers. The manuscript will undergo copyediting, typesetting, and review of the resulting proof before it is published in its final form. Please note that during the production process errors may be discovered, which could affect the content. All legal disclaimers that apply to the Communications of the Association for Information Systems pertain. For a definitive version of this work, please check for its appearance online at http://aisel.aisnet.org/cais/. 


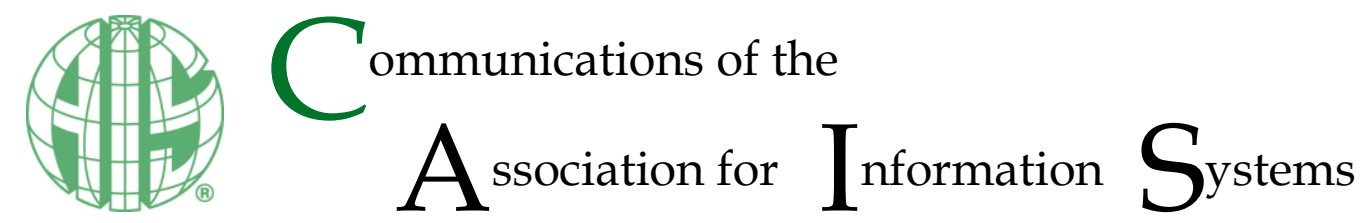

\title{
Champions of IS Innovations
}

\author{
Jaco Renken \\ Centre for Development Informatics, University of \\ Manchester \\ jaco.renken@manchester.ac.uk
}

\author{
Richard Heeks \\ Centre for Development Informatics, University of \\ Manchester \\ richard.heeks@manchester.ac.uk
}

\begin{abstract}
:
Champions have been studied in diverse settings and kinds of initiatives; a significant body of work is also growing steadily in the information systems field. However, there is still a lack of clarity about the distinctiveness of IS champions. Given the poor track record of IS project success and champions' importance to that success, the paper argues that this lack of conceptual clarity about the uniqueness of IS champions constitutes a significant and urgent gap. In part, this gap exists because of inadequate consolidation of knowledge about IS champions thus far. In response, we follow a systematic literature review by approaching this gap from two viewpoints: a research process perspective whereby we investigate the approaches and practices followed in IS champion research; and a thematic perspective whereby we examine progress with the accumulation of knowledge about IS champions to date. Our findings culminate in three contributions: 1) Eight IS champion distinctive features are proposed using a classification scheme; 2) A refined definition of IS champions is offered which better reflects the distinctiveness of the champion role in IS innovation; 3 ) Findings from process and thematic perspectives are combined in an agenda to take IS champion research forward.
\end{abstract}

Keywords: IS Champions; IS Innovation; Systematic Literature Review; Research Agenda. 


\section{Introduction}

The 'champion' concept is widely recognized and used. But what is a 'champion'? Broadly speaking, it is someone taking up a cause and becoming an advocate of it ${ }^{1}$. Champions are special kinds of leaders who voluntarily carry the flag for specifically chosen causes and mobilize others to join in (Taylor et al., 2011). Their enthusiastic promotion of a particular matter and persistence in the face of strong opposition have been noted since the earliest description of champions by Donald A. Schön in 1963. Most importantly, these individuals are known for playing a critical role in whatever initiative they become involved in.

Champions are well known in areas such as medical and health sciences, environmental science, marketing, education, and sport science as well as in the area of technological innovation (Shane, 1994; Howell and Boies, 2004; Sergeeva, 2016). Champions are also commonplace in the information systems (IS) field (Esteves and Pastor, 2002; Bassellier et al., 2003; Kamal, 2010; Van Laere and Aggestam, 2015). The champion concept made its way into the IS literature in the 1980s. Since then, research about these key individuals and their role in IS projects has appeared sporadically in academic writings. Today, a definition by Roure (1999) is often used in the IS literature to describe champions:

"any individual who made a decisive contribution to the innovation by actively and enthusiastically promoting its progress through critical stages in order to obtain resources and/or active support from top management". (Roure, 1999:4)

The occurrence of 'champions' in diverse disciplines raises a question: What is distinct about IS champions? This question has not been answered to date, but a first approach is to acknowledge two conceptually distinctive characteristics of IS as the subject of their championing. Firstly, IS are innovations; fitting Rogers's definition of an innovation: "an idea, practice, or object that is perceived new by an individual or other unit of adoption" (2003:11). The innovative objects are informational, such as new data or information sets and flows; and technological, such as new ICT products or services. The innovative practices are organisational, managerial or social, such as changing work processes, organisational structures or business strategies (Swanson, 1994). This combination of social, informational and technological aspects is the second distinguishing IS characteristic, also known as the socio-technical nature of IS (Avgerou, 2003). Socio-technical innovations are therefore the rather distinct subject of championing in the IS field and more accurately reflect the phenomenon of interest in this paper, namely champions of IS innovations, or IS champions in short. Because IS innovations are distinct, we argue that the roles, competencies and identities of IS champions are likely to be somewhat distinct from those in other disciplines.

Still, the implications of these unique characteristics of IS innovation for champions remain largely unclear. Reviewing the extant literature, it became apparent that very few studies explicitly endeavour to frame IS champion characteristics as distinct; questions about the uniqueness of IS champions are not asked and comparisons with champions in different domains are absent. Second, no cross-cutting review of what the literature says about champions in the IS domain could be found; a synthesis of the IS champion literature would be essential to consolidate knowledge about IS champions and to provide important indications about what future directions research on this topic might take.

We argue that this lack of conceptual clarity about the uniqueness of champions of IS innovations constitutes a significant and urgent gap in the literature. It is significant because key individuals such as champions are linked to IS project performance ${ }^{2}$ as a critical success factor (e.g. Schmidt et al., 2001; McManus and WoodHarper, 2007; Cerpa and Verner, 2009; Standish Group, 2009; Dwivedi et al., 2015). In a recent synthesis of IS project performance literature, Irvine and Hall (2015) found the top three most cited success factors to be about the roles of key individuals, such as champions, in IS projects. It is therefore very significant for the success of IS projects that knowledge about the roles, competencies and characteristics of IS champions be better aggregated.

Moreover, addressing the lack of knowledge building about IS champions is urgent because of the continuing poor track record of IS projects, with only a minority being held to have succeeded. To illustrate, an optimistic estimate is that no more than a third of those started between 2011 and 2015 have reached

\footnotetext{
1 "Person who voluntarily takes extraordinary interest in the adoption, implementation, and success of a cause, policy, program, project, or product." http://www.businessdictionary.com/definition/champion.html

${ }^{2}$ For the reasons outlined above, IS projects are regarded as IS innovations because they introduce new objects and practices to their adopters
} 
their full potential whilst about $20 \%$ will end in complete failure (Hastie and Wojewoda, 2015). We therefore set ever-growing investment in IS projects, continuing high failure rates, and the known significance of key individuals, such as champions, to their success, alongside our lack of consolidated knowledge about IS champions. In this situation, we argue the urgency of more complete, adequate and coherent knowledge accumulation about such champions.

Our purpose therefore is to contribute to this knowledge gap around the nature and potential uniqueness of IS champions. It is our aim to consolidate IS champion knowledge to date, thereby revealing cumulative insights and providing a baseline for future work that might most productively advance our understanding about these key individuals. A three-fold approach is followed. We firstly examine IS champion research approaches and practices to date because such understanding is essential for evaluating the reliability and rigour of the knowledge created thus far. Secondly, IS champion research is thematically examined to draw out key conceptualisations, amongst which will be potentially unique features. Thirdly, specific knowledge gaps and priorities will be identified in order to enable more complete and coherent knowledge accumulation about IS champions in future. To achieve its overall aim, the paper therefore seeks to answer three questions:

RQ 1: How are IS champions researched and by whom?

RQ 2: What has research so far told us about IS champions and what might be their unique characteristics?

RQ 3: What might be the priorities for future research on IS champions?

The paper begins with a brief outline of the systematic literature review method we have followed Further details of that method - identification and selection of literature and quality appraisal of sources - then follow. Results of evaluating IS champion research approaches and practices are presented next. Findings about IS champions - divided into seven thematic areas - come next, followed by conclusions about the uniqueness of IS champions and implied future research.

\section{Research Method}

A systematic and analytic approach was followed in conducting this review of the literature, motivated by three considerations:

- Criticism of IS scholars for being slow to adopt rigorous methods of literature review (Webster and Watson, 2002; Levy and Ellis, 2006; Jennex, 2015).

- The absence, to our knowledge, of any such review to date of IS champions despite, as noted above, their acknowledged importance.

- The accumulation of a critical mass of literature of relevance to IS champions, sufficient to be amenable to systematic literature review (SLR).

In this analysis, we follow the four-phased SLR strategy of Okoli and Schabram (2010) given its specific relevance to the IS domain. Table 1 outlines the four phases - i) Planning; ii) Selection; iii) Extraction; and iv) Execution - with brief descriptions of the eight composite steps. Summaries of application and implementation in this project are provided for each step. 
Table 1. Approach for Conducting the Systematic Literature Review (adapted from Okoli \& Schabram, 2010:7)

Step 1: Purpose

The purpose and intended goals for the review must be clearly and explicitly identified.

- To consolidate IS champion knowledge to date in order to identify distinctive features and reveal cumulative insights of championing in the IS domain as a baseline for future research (as detailed in the Introduction).

\section{Step 2: Protocol}

Before the review commences, a detailed protocol must be developed to ensure a systematic, repeatable and reliable approach is followed. This is a plan that describes the procedures used for every step of the review. It is particularly important when more than one reviewer is involved (as in this review) to ensure clarity and agreement about procedures. The protocol should be documented.

- Search terms were identified through iterative analysis of articles citing Schön's (1963) original work

- Innovation and IS literature were confirmed as relevant fields for IS champions research

- Google Scholar was chosen as the search engine following consideration of alternative databases because:

o It is freely-accessible and thus allows anyone to reproduce the search

- It provides readily-accessible citation information: an important aspect at the start of an SLR

- It is broad and non-disciplinary where other tools are narrower and discipline-specific

- It has the widest coverage of scholarly documents (Khabsa and Giles, 2014) compared to alternatives

- A repeatable search strategy was devised (summarized in Table 2)

- A multi-reviewer protocol was developed, piloted and refined (see Steps 3-5 and protocol in Appendix A).

Step 3: Searching for the Literature

The rationale and procedure followed to search for the literature requires explicit and detailed description. The search needs to be repeatable and its comprehensiveness justified.

- The search strategy was applied using Google Scholar; it yielded 255 results taken forward to Step 4.

\section{Step 4: Practical Screening}

Search results are screened for inclusion in the review. The criteria for including sources (and by implication excluding others) are derived from the purpose, and need to be explicit. This is a high-level assessment aimed at $z$ eliminating the obviously irrelevant works. The practical reasons for eliminating studies without further examination should be reported.

- All 255 sources were screened for inclusion on the basis of being:

- focussed on individual champions as the unit of analysis

- empirical research reports with primary data explicitly collected and used for the purpose of the study, to ensure these were original additions to the domain

- situated within the IS or Innovation studies discipline literature or published in the cognate field of business and management and relating to IS or other technological innovations

o peer-reviewed sources as a method of controlling for quality

- electronically-available sources required for computer-based content analysis

- Using this criterion, 33 sources were selected for inclusion, with 222 rejected; all the rejected sources were carefully documented and independently verified by two reviewers.

\section{Step 5: Quality Appraisal}

Following practical screening, the remaining works are screened for exclusion. This step necessitates a more detailed content assessment and the reviewers should be explicit about the criteria used. The purpose, aims and objectives of the review will influence the measures used during this appraisal.

- Using a more in-depth assessment of content, based on the Step 4 criteria, an additional eleven sources were z excluded: seven for being non-empirical papers (Mohi Uddin, 2000; Howell, 2005; Sipior, 2005; Coakes and 으 Smith, 2007; Molloy and Kriz, 2012; Renken and Heeks, 2013; Renken and Heeks, 2014), one due to lack of U evidence of peer review (Appolis and Alexander, 2013), three because the focus was on the championing of $\llbracket$ non-technological innovations (Lichtenthaler and Ernst, 2009; Bankins et al., 2017; Fujii, 2017).

- A final collection of 22 sources was yielded and formed the basis of analysis.

\section{Utep 6: Data Extraction}

Applicable information will be systematically extracted from the final collection of papers. A guide and assessment procedures, established during protocol development, will be used to extract raw data for synthesis in the next step.

- The quantitative and qualitative content analysis of the selected sources were done using a scoring form (see Appendix A) with thirty variables and associated measures (see Appendix B for a summary of the data that was extracted during content analysis).

Step 7: Synthesis of Studies

This is the main analytic phase of the review and involves combining, comparing and contrasting of qualitative and $z$ quantitative data collected during the extraction phase.

- IS champion research approaches and practices were analysed to evaluate the reliability and rigour of the knowledge created thus far (Section 3)

- An inductive approach was followed to identify key thematic areas which served as a framework for analysis (Section 4)

Step 8: Writing the Review

Results of the systematic literature review are reported. 
The first step, stating the purpose of the review, was addressed in the Introduction. Steps $2-5$ focus on the identification, selection and screening of the literature for review, and these form the content of the section that follows. The outputs of the final review steps are covered under the sections "Champion Research Approaches and Practices" and "Thematic Analysis and Findings". Potentially distinctive IS champion characteristics and recommendations towards a future research agenda are offered throughout and are summarized within the concluding part of the paper.

\subsection{Identification and Selection of the Literature}

SLR necessitates explicit clarification and justification of the search procedure when developing the protocol. An initial exploration of the IS literature showed seminal empirical research of relevance to IS champions is often drawn from the Innovation literature - the disciplinary birthplace of the champion concept. The search therefore needed to include both Innovation and IS literature in order to capture the core body of knowledge about championing IS-related technological artefacts and innovations.

As a pilot procedure, a search for articles citing Schön's (1963) work (whose "... discussion of champions serves as the starting point for most writers concerned with championship", Howell and Higgins (1990c:250)) was done. From these search results it became clear that a range of different terminologies is used to refer to champion-type individuals, but one or more aspect of the Roure definition, and our refinement about socio-technical innovations being the subject of championing in the IS field, are often omitted from the conceptualization. For example: 'change agents' is used (e.g. Markus and Benjamin, 1996), but this conceptualization focuses on a narrow view of the champion role - getting users to accept new technology - whilst their engagement with the innovation process is not considered. The terms 'promoters', 'brokers' or 'intermediaries' (Sarkar et al., 1995) have similar limitations, in these instances they focus only on individuals' advocacy of new technology or the brokerage role between different stakeholder groups, but not on the fuller range of technical, social and organisational elements of relevance to championing IS. In sum, the IS champion role encompasses more than these terminologies and their associated conceptualizations. We therefore limited search results to those containing 'champion' or 'champions' in the title - this was found to be effective in identifying articles conceptualizing IS champions in the full sense of the Roure definition and socio-technical role. Additionally, this approach aided with identifying those explicitly focussing on champions as the unit of analysis. This procedure yielded 59 articles originating from a variety of disciplines including IS and Innovation.

From this limited set of works, titles and abstracts were examined to identify commonly-used terminology, thereby forming a basis from which to identify potential search terms. This was an iterative process whereby identified terms were added, the search repeated and the results evaluated. Google Scholar was selected to implement the search strategy for reasons outlined in Table 1. The final set of search terms and strategy are summarized in Table 2.

Table 2. Summary of Google Scholar Literature Search Strategy

\begin{tabular}{|l|l|}
\hline Search string & $\begin{array}{c}\text { allintitle: champion OR champions AND (project OR technology OR technological OR } \\
\text { innovation OR "information system" OR IT OR role OR "non champions") }\end{array}$ \\
\hline Time period & $1990-2017$ \\
\hline Exclude & i) patents, ii) citations and iii) non-English results \\
\hline Final search date & 30 January 2018 \\
\hline
\end{tabular}

The remainder of the search terms mainly dealt with the context or object of championing (project, technology, technological, innovation, information system, IT). The 'role' and 'non-champion' terms were added when it became apparent that, without these, some key sources identified during preliminary searches were not appearing in Google Scholar.

Further refinements were made in order to isolate the most relevant sources. We wanted to focus our attention on contemporary literature and chose 1990 as the most-recent date which would allow inclusion of the most-cited sources of relevance to IS champions (those authored by Howell). Furthermore, the literature on champions has steadily grown since Schön's work in the early 1960s, but it was only from the 1990s onwards that research into the championing of ICTs become commonplace. The scope of the review is therefore limited to the period as per Table 2. Patents, citations and non-English results were excluded.

The 255 identified sources were screened for inclusion using the criteria outlined in Table 1; this process yielded 33 sources selected for inclusion, with 222 rejected due to not meeting one or more criterion. The 
second phase of our SLR approach was thereby completed. The third phase of the review - data extraction - involved quantitative and qualitative content analysis which we turn to next.

\subsection{Quality Appraisal and Data Extraction}

The remaining 33 sources were screened for exclusion through quality appraisal which undertook a more in-depth assessment of content. Two reviewers independently assessed sources using the five inclusion criteria set out in Table 1 resulting in the exclusion of a further 11 articles. Thus, at the point of entry to data extraction (Step 6), a final collection of 22 sources - presented chronologically in Figure 1 - was used as the basis for this review of the body of knowledge about IS champions.

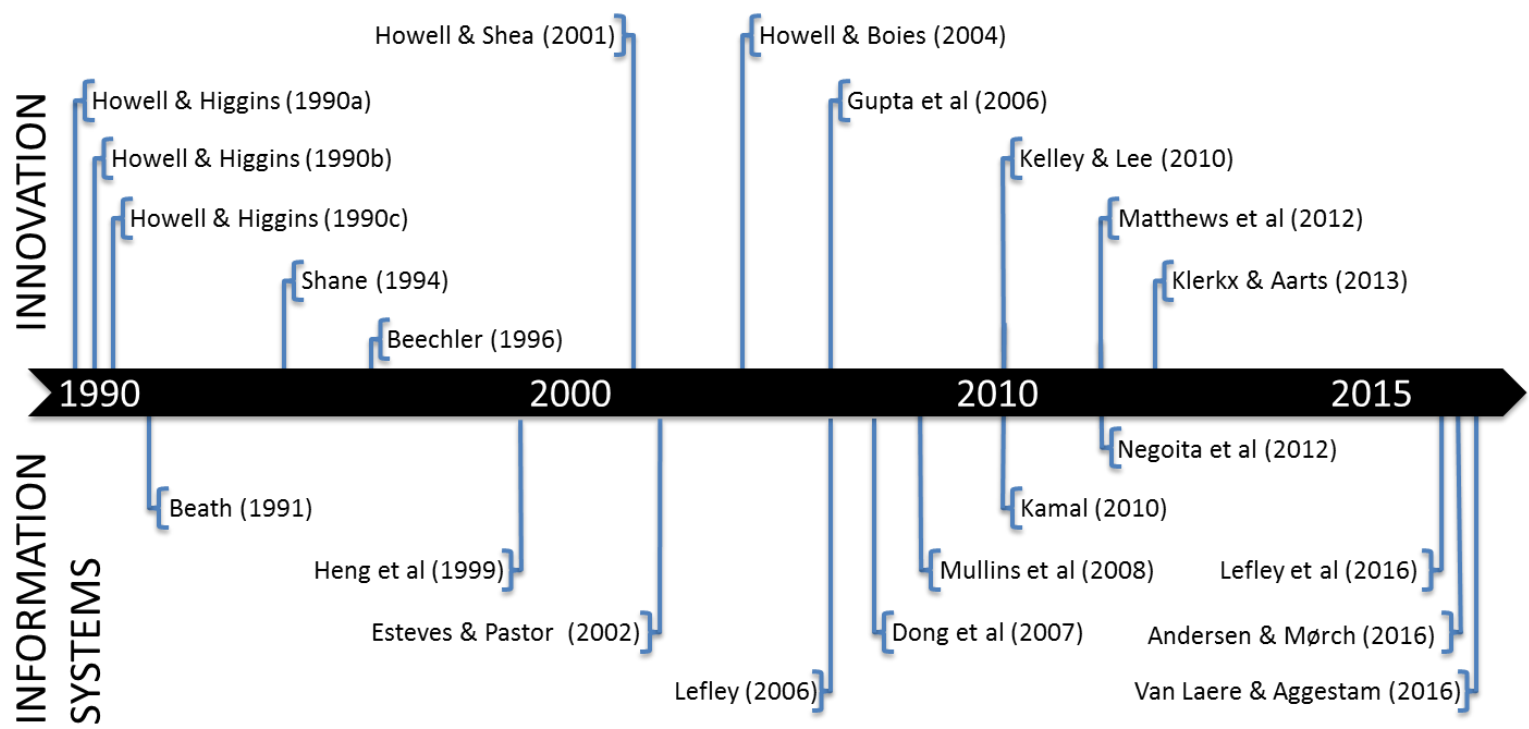

Figure 1. Champion Literature Timeline

Reflected on Figure 1, a balance between Innovation (11) and IS (11) sources was obtained. From the Innovation literature, champion research emerged at fairly regular intervals throughout the period. It provides an indication of on-going interest in champions and their role in the innovation process. Champion research in the IS literature, however, is concentrated in the latter half of the period under consideration, coinciding with the widespread diffusion of ICTs in general and the Internet in particular. This evidence of sustained interest in champions from the Innovation literature, coupled with a growing interest from the IS literature is offered as additional motivation for the timeliness and significance of the current review.

Data was extracted through a comprehensive, pre-piloted procedure using a scoring form (Appendix A); and a summary of the extracted data is provided in Appendix B. The iterative process of testing and refining measures and procedures we followed resonates well with the experiences of Okoli and Schabram (2010). Within the obvious confines of our own resources, the criteria and procedures for the content analysis are reliable, repeatable and unambiguous. Our analytical review is presented in the two sections following.

\section{Champion Research Approaches and Practices}

The aim of this section is to answer our first research question about the approaches and practices that are used to research IS champions. Our findings form the basis from which we make recommendations.

\subsection{Bibliographic Analysis}

Criteria for inclusion required sources to be peer-reviewed as a measure of quality control, resulting in the types of papers being restricted to journal articles (16), conference proceedings (5), and a single working paper. It was important to gain insight into who researches IS champions and how they deliberate because research traditions differ between disciplines; insights into this knowledge production system will be valuable to help understand the nature of knowledge accumulation. 
This collection of papers was authored by 42 unique individuals originating from a variety of disciplinary backgrounds as depicted in Figure 2.

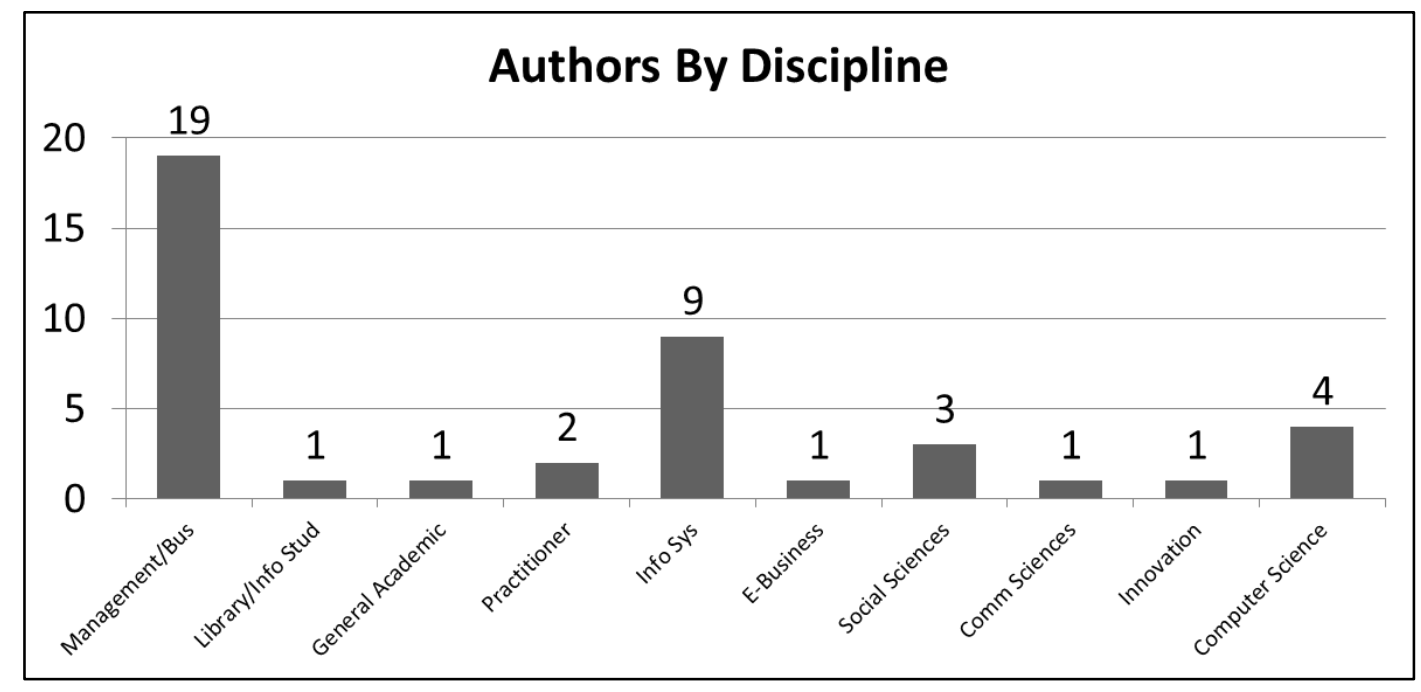

Figure 2. Contributing Authors' Disciplinary Background

Figure 2 shows that the majority of scholars originate from a management or business background (45\%) and just over one fifth $(22 \%)$ are IS scholars. Together these two groupings capture the bulk of IS champion research. The remaining third is made up of scholars from eight cognate disciplines, which is evidence of the widespread interest in champions. It also shows the potential for multi- and inter-disciplinary research. However, only six of the reviewed papers were co-authored by colleagues from different disciplinary backgrounds, which indicates the limited realisation of this potential.

The Figure 2 analysis opens up questions about who the most influential IS champion scholars are and about the effectiveness of communication between different scholars through their publications. Citation patterns between the reviewed papers were therefore explored; the results are presented in Figure 3.

Figure 3 illustrates a citation network diagram where the nodes represent papers and citations are indicated by the one-directional links originating from the cited source. The size of a node is proportionate to the number of times it is cited by other papers in the diagram; papers that are most often cited in IS champion research are therefore the largest. The set of 22 reviewed papers is presented as blue squares. Red circles represent eight champion sources from prior to the reviewed period; these were identified through a bibliographic analysis of the selected papers. The Figure 3 citation network diagram provides the basis for analysing the importance of individual papers as well as the nature of communication in the corpus of IS champion literature.

Jane M. Howell is the lead author in three of the four most-cited articles in this collection. The results show that she is, second to the seminal work of Donald A Schön (1963), the most influential scholar in this area, suggesting that her work (including Howell, 2005) should be reviewed by anybody interested in researching IS champions.

Communication between sources is important as a means to incrementally build knowledge in an area of research. An analysis of the Figure 3 network shows that papers cite an average of 1.6 other sources in the selected literature. This average increases to 3.6 citations per paper when adding the links to the pre-1990 champion research. We conclude from this finding that IS champion research is carried out in a rather isolated manner, forfeiting the full benefit of incremental knowledge accumulation in the area. This aspect will be further explored when analysing the theory bases in section 3.3.

\section{Research Recommendations:}

i. While the interdisciplinary interest in champions of IS innovation is encouraging, there is an opportunity for more native IS scholars, with first-hand understanding of the contextual ICT element, to contribute.

ii. Only six of the papers were authored by multi-disciplinary teams; as will be argued in the thematic analysis, context and contingent factors are very important to understand IS champions. Increasing 
the disciplinary diversity of research teams - specifically involving more practitioners, innovation studies and social science researchers - is therefore recommended.

iii. The limited communication between papers in the corpus of IS champion literature, evidenced by the low citation rate, leads to a recommendation that authors should engage much more with prior IS champion research in order to maximize incremental knowledge building. This review paper is offered as an access point to the relevant body of literature.

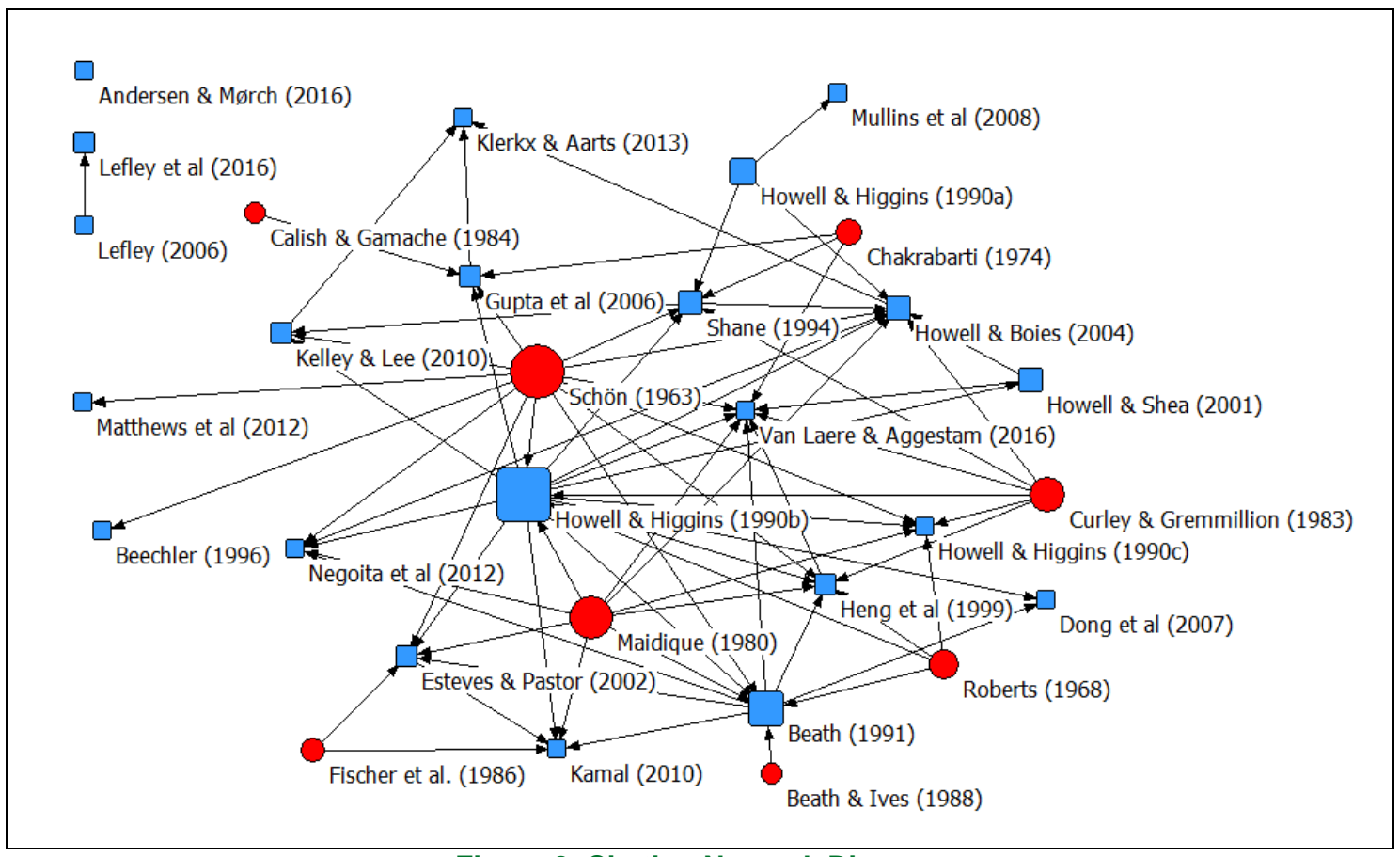

Figure 3. Citation Network Diagram

\subsection{Research Philosophy}

The underpinning philosophical assumptions and congruency of research design and strategy has bearing on the type and quality of knowledge created; it has bearing on how reliability, validity, rigour and quality of a study are perceived (Becker and Niehaves, 2007). With our aim to consolidate IS champion knowledge to date thereby revealing cumulative understandings, it is important to gain insight into the philosophical approaches followed in IS champion research.

The familiar categorization of research philosophies consisting of positivism, interpretivism, critical research, and critical realism (as per Mingers, 2004b) formed the basis of our analysis ${ }^{3}$. Results of the content analysis as it pertain to research philosophies are summarized in Appendix B; our synthesis and interpretation follow.

In the set of 22 reviewed papers, only two explicitly stated their philosophical perspective; for the remainder, this had to be interpreted. From this, $86 \%$ were found to be positivist (10 papers explicitly treat phenomena as real and objective; nine papers treat some phenomena as real, but do not ascribe cause or mix some positivism with notions of constructivism). Only two papers follow interpretive approaches (9\%). For one paper the research philosophy could not be evaluated. None of the reviewed papers approached champion research from the critical or critical-realist perspectives. So, what do these results reveal about IS champion research?

To interpret these results, we briefly turn to the philosophical traditions prevalent in IS literature. In one of the earliest cross-cutting analyses of IS research, Orlikowski and Baroudi (1991) evidenced the philosophical homogeneity in the field; positivism accounted for $96.8 \%$ and interpretive studies represented the remaining $3.2 \%$ of their sample. This they described as "unnecessarily restrictive"; they argued for the

\footnotetext{
${ }^{3}$ We acknowledge several classifications of IS research paradigms have been used over the years (Burrell and Morgan, 1979; Fitzgerald and Howcroft, 1998; Monod, 2003; Chen and Hirschheim, 2004; Weber, 2004), but decided to use the Mingers' categorization as it fits earlier literature on which our arguments are based.
} 
usefulness of alternative paradigmatic approaches and that "much can be gained if a plurality of research perspectives is effectively employed to investigate information systems phenomena" (1991:1).

We similarly argue that the relative positivist monoculture limits IS champion knowledge generation and accumulation in a non-trivial way. For example, reflected in the belief that an objective reality exists and that natural phenomena can be known and studied, the positivism inherent in most of the IS champion literature led it to ask questions such as 'How do IS champions differ from non-champions in terms of their skills, preferences and leadership behaviours?', 'Are the differences between champions and non-champions universal or shaped by local culture or domain?' and 'What are the skills that enable champions to be successful in promoting IS?'.

Different philosophical approaches would ask different questions about the phenomenon of interest (Monod, 2003), but such questions are largely missing to date. For example, interpretivism believes that reality is a subjective social construction created in the minds of people while interacting in the world. The aim of IS champion research from this perspective is to understand the human and social interactions whereby people construct their subjective meanings about reality. As such, interpretivists would explore questions such as 'What are the important aspects of a champion's role understood to be?', 'How does organisational culture influence IS champion performance?' and 'How do IS champions build relationships with other stakeholders?'. The two interpretive studies included in the review (Heng et al., 1999; Kamal, 2010) demonstrated the unique types of knowledge about IS champions that can be gained compared to positivist studies. Indeed, as will be demonstrated in section 4, there are many knowledge gaps in our understanding of the distinctiveness of IS champions that could fruitfully be pursued using the interpretive approach.

Critical IS research challenges the status quo of organisations and information systems to expose inconsistencies and contradictions in the social system (Orlikowski et al., 1991). A critical approach would thus provoke questioning of the notion of IS champions, seeking to understand in whose interests those champions act, analysing the power of champions and of the innovations they champion, and raising the possibility of alternative approaches. We ascribe the deficiency of insights into these important aspects, at least in part, to the lack of engaging in critical IS champion research.

Lastly, critical realism assumes the independent existence of phenomena separate from human cognition, on the one hand, but acknowledges that production of knowledge is a human activity that is always socially and historically located. Its focus on deep causal explanations would be valuable in generating better understanding of the big questions around IS champions: "Where do they originate from, and why?"; "How can they be developed?"; "What are the positive, and potentially negative impacts of champions on IS projects?".

In sum, our analysis of the philosophical approaches followed in IS champion research suggests dominance of positivism brings some significant limitations to IS champion knowledge generation.

\section{Research Recommendations:}

iv. The reliability and validity of IS champion research can be improved by being explicit about its philosophical underpinnings, and then following guidelines for rigour within the chosen philosophy. This could be encouraged if reviewers sought such explicitness and reflectiveness from is champion researchers. Studies can also be evaluated in terms of the consistency with which phenomena are treated analytically, and the congruence of research findings with philosophical assumptions.

v. The antidote to the prevailing positivist monoculturalism in IS champion research is to diversify into alternative philosophical approaches. Other philosophies, including critical research and critical realism, hold the potential to inform champion research in new ways.

\subsection{Theory Base}

The theoretical base of a paper refers to the framework of knowledge that was used in the IS champion research. We included analysis of the types, roles and value of theory in IS champion research for three reasons. First, because theory guides what can be uncovered about IS champions and any theoretical skews may also skew what we know about the topic. Second, because diversity or otherwise of theory use offers insights into the level of aggregation or fragmentation of knowledge about IS champions. Third, and following Lewin's famous phrase of there being 'nothing quite so practical as a good theory', choice of theory guides the nature of practical recommendations from IS champion research. The frameworks of knowledge were explored through three analytical activities that will now be outlined. 
Analysis 1. In some instances the framework of knowledge takes the form of a named theory, such as a theory of Social Capital .At other times the framework of knowledge is best captured by identifying the theoretical constructs used in the analysis or produced through theory building. Table 3 presents the content analysis of theories and theoretical constructs ${ }^{4}$ featuring in the set of papers.

Table 3. Theories and Theoretical Constructs used in the Collection of Papers

\begin{tabular}{|c|c|c|}
\hline ID & Theories \& Constructs & Relevant Papers \\
\hline 1. & Champion roles & $\begin{array}{l}\text { Beechler (1996); Esteves \& Pastor (2002); Gupta et al (2006); } \\
\text { Lefley (2006); Kamal (2010); Matthews et al (2012); Klerkx \& Aarts } \\
\text { (2013); Van Laere \& Aggestam (2016) }\end{array}$ \\
\hline 2. & $\begin{array}{l}\text { Leadership } \\
\text { (including Transformational Leadership) }\end{array}$ & $\begin{array}{l}\text { Howell \& Higgins (1990a, 1990b, 1990c); Heng et al (1999); Dong } \\
\text { et al (2007) }\end{array}$ \\
\hline 3. & Champion influence tactics & Howell \& Higgins (1990b, 1990c); Negoita et al (2012) \\
\hline 4. & Champion emergence & $\begin{array}{l}\text { Howell \& Higgins (1990b); Howell \& Boies (2004); Negoita et al } \\
(2012)\end{array}$ \\
\hline 5. & Champion impact on project & Howell \& Shea (2001); Esteves \& Pastor (2002); Lefley (2006) \\
\hline 6. & Personality characteristics & Howell \& Higgins (1990a, 1990b) \\
\hline 7. & Champion support & Beath (1991); Kelley \& Lee (2010) \\
\hline 8. & Champion behaviour & Howell \& Shea (2001); Van Laere \& Aggestam (2016) \\
\hline 9. & Network theory & Gupta et al (2006); Klerkx \& Aarts (2013) \\
\hline 10. & Technology Acceptance Model (TAM) & Dong et al (2007); Mullins et al (2008) \\
\hline 11. & Career experience & Howell \& Higgins (1990a) \\
\hline 12. & Championing process & Howell \& Higgins (1990a) \\
\hline 13. & Social Deviance & Shane (1994) \\
\hline 14. & Champion types & Heng et al (1999) \\
\hline 15. & Champion innovativeness & Kelley \& Lee (2010) \\
\hline 16. & Champion empowerment & Kelley \& Lee (2010) \\
\hline 17. & Champion resource requirement & Kelley \& Lee (2010) \\
\hline 18. & Champion managerial control & Kelley \& Lee (2010) \\
\hline 19. & Financial Appraisal Profile (FAP) model & Lefley (2006) \\
\hline 20. & Innovation Theory & Mullins et al (2008) \\
\hline 21. & Social Capital & Negoita et al (2012) \\
\hline 22. & Schön's Reflection in Action & Matthews et al (2012) \\
\hline 23. & Cultures of Participation & Andersen \& Mørch (2016) \\
\hline 24. & Optimism Bias Theory & Lefley et al (2016) \\
\hline
\end{tabular}

The variety in types of theory shown in Table 3 means IS champion research is not theoretically monocultural; this theoretical diversity is most likely a consequence of the multidisciplinary interest pointed out earlier. Moreover, almost half (10/24) of the theories or constructs feature in multiple studies showing variety in theory use; this, in principle, suggests theory building could be taking place whereby subsequent authors contribute to the improvement of theoretical understandings gained from earlier work. However, analysis of the citation patterns between the papers, presented earlier in Figure 3, indicates that sources do not often build on prior work or even establish such connections through cross referencing. The potential strength of theoretical variety leading to aggregation in IS champion research is therefore not yet fully realised.

Consider, for example, the most common theoretical construct from Table 3 (champion roles): only two of the eight studies referenced another (Kamal (2010) cited Esteves \& Pastor (2002); Klerkx \& Aarts (2013)

\footnotetext{
4 'Theoretical constructs' refers to existing theoretical notions that are either incorporated as input to the study, or new theoretical notions that emerged as the product of analytical induction from the study. 'Theories' refers to known frameworks of knowledge, such as the Technology Acceptance Model (TAM), for example. This analysis treated theories and theoretical constructs the same, since the aim was to take stock of all aspects of IS champions that are theorized in the literature.
} 
cited Gupta et al (2006)). Consequently very little progress has been made in terms of building a body of theoretical understanding about the unique roles of IS champions. Overall, the analysis of Table 3 and Figure 3 reveal the prevalence of theoretical individualism in the reviewed IS champion literature: authors consider their theorizing about IS champions largely in isolation, with little regard for similar prior work.

Analysis 2. To explore the types of theories featuring in IS champion studies we turn to Shirley Gregor. She defined theory (in IS) as: "statements that say how something should be done in practice; or, statements providing a lens for viewing or explaining the world; or, statements of relationships among constructs that can be tested" (2006:613). And she developed a taxonomy of five theory types based on different configurations of four characteristics: inclusion of causal explanations; presence of testable propositions; ability to provide predictions; and extent to which theory is prescriptive. Table 4 presents an overview of Gregor's taxonomy applied in order to classify the reviewed sources.

Table 4. A Taxonomy of Theory Types Applied to IS Champion Research (based on Gregor, 2006)

\begin{tabular}{|c|c|c|c|c|c|c|}
\hline Theory Type & Distinguishing Attribute & 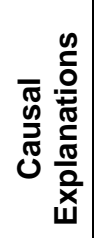 & 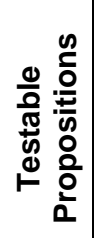 & 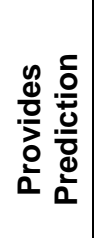 & 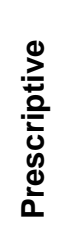 & $\begin{array}{l}\text { Classification of IS Champion } \\
\text { Papers }\end{array}$ \\
\hline $\begin{array}{l}\text { I. ANALYSIS } \\
\text { e.g. Design-Reality } \\
\text { Gaps; Taxonomies; } \\
\text { Frameworks }\end{array}$ & $\begin{array}{l}\text { Says what is. The theory does not } \\
\text { extend beyond analysis and } \\
\text { description. No causal } \\
\text { relationships among phenomena } \\
\text { are specified and no predictions } \\
\text { made. }\end{array}$ & - & - & - & - & $\begin{array}{l}\text { Beechler (1996) } \\
\text { Heng et al (1999) } \\
\text { Lefley (2006) } \\
\text { Kelley \& Lee (2010) } \\
\text { Kamal (2010) } \\
\text { Matthews et al (2012) } \\
\text { Klerkx \& Aarts (2013) } \\
\text { Andersen \& Mørch (2016) } \\
\text { Lefley et al (2016) } \\
\end{array}$ \\
\hline $\begin{array}{l}\text { II. EXPLANATION } \\
\text { e.g. Theories of } \\
\text { understanding: } \\
\text { Structuration } \\
\text { Theory; Cases } \\
\text { revealing drivers/ } \\
\text { barriers/ CSFs }\end{array}$ & $\begin{array}{l}\text { Says what is, how, why, when, } \\
\text { and where. The theory provides } \\
\text { explanations but does not aim to } \\
\text { predict with any precision. There } \\
\text { are no testable propositions. }\end{array}$ & $\checkmark$ & - & - & - & $\begin{array}{l}\text { Negoita et al (2012) } \\
\text { Van Laere \& Aggestam (2016) }\end{array}$ \\
\hline $\begin{array}{l}\text { III. PREDICTION } \\
\text { e.g. Moore's Law }\end{array}$ & $\begin{array}{l}\text { Says what is and what will be. } \\
\text { The theory provides predictions } \\
\text { and has testable propositions but } \\
\text { does not have well-developed } \\
\text { justificatory causal explanations. }\end{array}$ & - & $\checkmark$ & $\checkmark$ & - & $\begin{array}{l}\text { Howell \& Higgins (1990c) } \\
\text { Beath (1991) } \\
\text { Esteves \& Pastor (2002) } \\
\text { Howell \& Boies (2004) } \\
\text { Gupta et al (2006) } \\
\end{array}$ \\
\hline $\begin{array}{l}\text { IV. EXPLANATION } \\
\text { AND PREDICTION } \\
\text { e.g. Cybernetics; } \\
\text { Soft Systems } \\
\text { Approach; } \\
\text { Complexity Theory; } \\
\text { TAM; Ideal Types }\end{array}$ & $\begin{array}{l}\text { Says what is, how, why, when, } \\
\text { where and what will be. Provides } \\
\text { predictions and has both testable } \\
\text { propositions and causal } \\
\text { explanations. }\end{array}$ & $\checkmark$ & $\checkmark$ & $\checkmark$ & - & $\begin{array}{l}\text { Howell \& Higgins (1990a) } \\
\text { Howell \& Higgins (1990b) } \\
\text { Shane (1994) } \\
\text { Howell \& Shea (2001) } \\
\text { Dong et al (2007) } \\
\text { Mullins et al (2008) }\end{array}$ \\
\hline $\begin{array}{l}\text { V. DESIGN AND } \\
\text { ACTION } \\
\text { e.g. Participative } \\
\text { Methodologies }\end{array}$ & $\begin{array}{l}\text { Says how to do something. The } \\
\text { theory gives explicit prescriptions } \\
\text { (e.g. methods, techniques, } \\
\text { principles of form and function) for } \\
\text { constructing an artefact. }\end{array}$ & $\checkmark$ & $\checkmark$ & $\checkmark$ & $\checkmark$ & \\
\hline
\end{tabular}

The Table 4 analysis moves beyond identification of theories (the previous analysis) by revealing the kinds of theories used in the reviewed IS champion literature. Type I, III and IV theories featured frequently in the collection of sources, while Type $\mathrm{V}$ theories - Design and Action - were absent, and Explanation theories (Type II) were only found in two studies.

To interpret these results, we draw on Sahay and Walsham (1995) who offer three arguments for the value of theory: it is a means for i) researchers to communicate with practitioners; ii) researchers to communicate 
with each other; and iii) accumulation of knowledge ${ }^{5}$. Each of these sources of value will now be considered in relation to IS champion research.

First, the contributions of champions to IS projects are decisively practical; theory-based, prescriptive statements that "specify how people can accomplish something in practice" (Gregor, 2006:620) are therefore important. Indeed, implications for practitioners, even from Type I-IV theories, do feature in the reviewed studies. To illustrate, Howell and Higgins (1990b) used a theory of transformational leadership to analyse the factors leading to champion emergence; their findings propose transformational leadership training as an effective means to enable individuals with certain "personal characteristics and social skills" (1990b:339) to emerge as champions. This type of communication with practitioners is theory-enabled and therefore a positive indication of the value of theory in IS champion research. However, there is a notable absence of Design and Action (Type V) theories from the reviewed sources; and this constitutes a research gap that will constrain the level of practical guidance.

The second 'value of theory' is derived from researchers communicating with each other: the use of similar theories to investigate different aspects, or different theories to study similar aspects, provide researchers with a common language to exchange ideas, challenge findings and further explore identified gaps. This, in turn, leads to a build-up of knowledge - the third 'value of theory' - as opposed to small, unconnected pockets of understanding about IS champions that might result. These two values are illustrated in the IS champion literature: for example, Dong et al. (2007) continued a discussion about transformational leadership behaviour of champions that Howell and Higgins (1990b) started earlier; not only comparing their work to that of Howell and Higgins, but extended it by establishing a correlation with the body of theory about individual technology beliefs, something quite distinctive about IS champions. However, more generally and as we have already argued based on the Table 3 and Figure 3 analyses, communication between IS champion researchers is limited, resulting in the largely under-realized potential for theory building.

What the present analysis cannot tell us is the areas of IS champion research that are not adequately theorized; something we will do later using Tables $3 \& 4$ in conjunction with knowledge gaps outlined in the second half of the paper. Next we analyse the role of theory in IS champion research.

Analysis 3. Geoff Walsham illustrated the different roles of theory (particularly in IS case studies, but also more generally) by linking it to different stages of the research process: "as an initial guide to design and data collection; or, as part of an iterative process of data collection and analysis; or, as a final product of the research" (1995a:76). These different roles of theory became visible when we analysed the diverse research approaches followed in the collection of papers (see Appendix B for a summary of extracted data on this).

Half of the studies set out, either explicitly (9) or implicitly (2), with some theory or concept for testing (hypothetic-deductive). Theory was therefore used as input to analyse IS champion constructs and test hypotheses; as such theory guided the research design, data collection and analysis. A further eight studies approximated setting out with some theory or concept and then testing it with data, followed by drawing conceptual inferences at a theoretical level (quasi hypothetic-deductive followed by inductive). Here the role of theory was three-fold: it served as input to the study design; it formed part of the analytical process; and, it was offered as research output. The remaining three studies began grounded in data and produced theory as a research output through the process of analytical induction (inductive or quasi-inductive).

This diversity of approaches to theory can be seen as a strength; a balance of theory testing and theory building suggesting value for theory in expanding IS champion knowledge. One result is that a few 'native' champion theories have already emerged. The inductive study of Van Laere \& Aggestam (2016), for example, yielded a theoretical conceptualisation of how the collective performance of multiple champions, in fluid contextual conditions, led to innovation success. In another example, Gupta et al (2006) developed a theory about the roles of IS champions in the creation of a new enterprise. These native IS champion theories are valuable to both researchers and practitioners who aim to harness the potential positive contributions of champions.

Furthermore, incremental knowledge building - one of the values of theory discussed earlier - can be amplified through different roles that theory plays in the research approach. Small instances of incremental theory development and refinement could be found in the collection of papers of which conceptualizing IS

\footnotetext{
${ }^{5}$ They argue a fourth value: strengthening legitimacy and recognition of the field as an academic discipline. However, as IS champion research is not aspiring to be a distinct academic discipline, this is not discussed here.
} 
champions as transformational leaders might be the most developed area to date. Howell \& Higgins (1990b, 1990c) initially tested this through hypothetic-deductive studies, followed by Heng et al. (1999) and Howell \& Boies's (2004) inductive work. Heng et al. (1999) extended the personality trait-based leadership conceptualisation of champions by evidencing the importance of organisational-level characteristics. Howell \& Boies (2004) took this further by tying leadership behaviours to the emergence of champions and their roles in the innovation process. However, even with this example of incremental theory building, the links between the earlier and later studies were rather weak; for instance, neither of the two examples frame their theoretical contribution in relation to the foundation studies.

This evidence shows that theory is valuable and does play a role in facilitating communication between researchers and in the incremental accumulation of IS champion knowledge, but we conclude that the potential is mostly untapped at present because of the relative isolation in which IS champion research has so far taken place.

\section{Research Recommendations:}

vi. The prevalence of theoretical individualism - limited engagement between studies that use similar theories - was revealed in the reviewed IS champion literature: authors consider their theorizing about IS champions in isolation, with little regard for similar prior work. We argue for a move towards theoretical collectivism - IS champion researchers communicating with each other through theory - whereby better incremental theory building can take place.

vii. A few native IS champion theories have already emerged; researchers are encouraged to pursue this further, particularly to develop practice-oriented (Type V) theories. For example, it would only take a small additional step for theories of champion emergence and champion support (as per Table 3) to become prescriptive; that is to prescribe steps to be taken and conditions to be created in order for champions to emerge, or, to recommend support actions for managers that would cause champions to promote IS more successfully.

viii. There is room to expand the range of theories in IS champion research by identifying existing theories with agency to illuminate under-theorized aspects. For example: Capability Theory (Sen, 1992) could yield novel insights into the competencies, roles and activities of IS champions; wellestablished, existing theories about personal characteristics, such as the Big Five personality traits (Goldberg, 1990), could bring together the many disconnected studies on aspects of champion traits; and, motivational theories, such as the Work Preference Index (Barba-Sánchez and AtienzaSahuquillo, 2012), could lead to deeper understanding of the motivations of champions.

\subsection{Research Strategies, Methodological Choices and Methods}

An evaluation of the reliability and rigour of IS champion research would be incomplete without examining research design choices and practices. Results of our assessment are summarized in Appendix B; we will now present our analytical conclusions.

Reviewed studies can be differentiated on the basis of research strategy - the overall plan of action to achieve the goals of the project (Palvia et al., 2004:529). Overall, a trend of following a relatively narrow range of common approaches - survey research (8), case studies (5 single cases; 3 multiple cases), field studies (4) and content analysis (2) - was found.

A similar trend to follow a fairly narrow range of common approaches also became clear from our analysis of data collection methods. Interviews - structured, semi-structured or unstructured - were the most common method, forming part of data collection strategies in 13 of the 22 studies. Questionnaires (or surveys) were part of the data collection strategy of 10 sources. Other strategies included one Delphi study, two studies using observations, a further two performing document analysis and one source performing a discussion analysis of website content. While plurality of research strategies and methods is not an end in itself, it is an expected part of the progression of knowledge creation in a field (Easterby-Smith et al., 2008). This limited diversity of strategy and method result in untapped potential to deepen and widen IS champion knowledge through alternative approaches.

A spread of methodological designs was utilised (see Appendix B): i) eight studies followed a qualitative approach - six of these were case studies; ii) seven studies followed a quantitative approach - all but one followed a survey strategy; and iii) seven studies followed a mixed-methods approach - two of those were field studies and two formed part of a survey strategy. Some alignment between research strategies and methodological designs could thus be detected. Whilst alignment of this nature is expected for survey 
research, the scarcity of mixed-method approaches in sources that followed a case strategy (only one mixed method case study was included) is notable; denying those studies the validity-related benefits of multimethod triangulation.

A further characteristic of the research approaches followed in the reviewed sources became evident from an analysis of the time profile of collected data (Appendix B). The data of 16 studies just related to a single time period with little or no regard for changes over time. Only four longitudinal studies were included where time was used as an important factor in the analysis. The remaining two studies included some trend analysis whereby the main element includes some kind of a history. Less than a third of the reviewed sources (6/22) used an approach that allowed the analysis of how champions change over time. This dominance of cross-sectional, single-period studies is problematic given that champions are change agents (Howell and Higgins, 1990a; Negoita et al., 2012) and a time dimension is fundamental to their role and activities.

\section{Research Recommendations:}

ix. Research strategies beyond the big three - surveys, case studies and field studies - hold the potential to yield new knowledge about IS champions. Examples include: ethnography - this strategy could yield valuable longitudinal insights into the impacts of champions over time; action research - this strategy is ideally positioned to contribute missing action-oriented theoretical insights identified earlier; and experiments - this strategy could advance the rigour of positivist IS champion research.

x. A range of alternative methods is available which could provide new insights for IS champion research. Two examples are: Social Network Analysis (SNA), which could deepen methodological and analytical rigour when answering questions about who IS champions draw resources from, the types of resources accessed through others and the influence tactics used to obtain needed resources; and, group interview which is a means to efficiently involve more stakeholders in the research and to identify distinctive IS champion themes not yet studied.

xi. Multiple perspectives, enabled through the use of mixed-methods, are likely to yield a better understanding of the phenomenon under investigation compared to insights gained from a single method (Creswell and Plano Clark, 2007). Mixed-methods is a small but growing trend in IS research (Venkatesh et al., 2013) which suggests an opportunity exists to further champion research in this way: the complex interactions between individual champions, organisational environment and innovative technology inevitably require unique combinations of multiple- and mixed-methods to create a cumulative body of knowledge.

\subsection{Champion Identification}

The importance and challenge of accurate champion identification was emphasised in one of the earliest sources (Howell and Higgins 1990b). Champions may be wrongly identified: relying on a single source or self-nomination (given that being a champion is "a socially desirable label" (ibid::318)) lacks rigour in differentiating between champions and non-champions. Or there may be no clear definition against which to verify 'candidate champions'. We therefore singled out champion identification in our appraisal - Table 5 presents a summary of the procedures followed in the 22 reviewed studies.

Deliberate attempts to ensure accurate champion identification - some more rigorous than others - were demonstrated in many of the studies. However, there are still instances where champions were not explicitly identified, or the authors did not include a clear description of the procedures they followed. Broadly explained, the more rigorous studies used multiple steps to identify champions. One of the steps typically involved peer nomination - people are asked who they think meets given criteria, usually based on a predefined definition. A next step typically involved verification of a nominated candidate - the final decision is therefore based on triangulation between nominators, verification interviews and researcher observations.

Less rigorous procedures involved only a single step to identify champions; the researchers typically identified 'candidate champions' during fieldwork, or simply relied on nominations from organisational representatives, or based their selection on a designated position in the organisation. Common weaknesses of these approaches are the lack of verification through triangulation, or even the lack of clear criteria against which candidates are compared. The least-rigorous studies are those which did not differentiate between champions and non-champions, or did not include any description of the identification procedures. 
Table 5. Identification of Champions

Howell \& Higgins (1990a) - 25
individuals were 'singled-out' from
$>150$ interviews with people from 25
companies and 28 successful IT
innovations.

Howell \& Higgins (1990b) - Peer nomination, classification of nominated individuals by nominee, based on $100 \%$ agreement on an individual by multiple nominees, verified through examining openended questions.

Howell \& Higgins (1990c) - Peer nomination, classification of nominated individuals by nominee, based on $100 \%$ agreement on an individual by multiple nominees, verified through examining openended questions.

Howell \& Shea (2001) - Nominated

by company executives, verified through interviews with the nominees.
Kelley \& Lee (2010) - Senior executives identified the champions in their divisions.
Esteves \& Pastor (2002) - No differentiation between champions and non-champions amongst respondents.
Kamal (2010) - Based on designated position in the organisation.
Howell \& Boies (2004) - Nomination by executives, followed by interviews with key individual who nominated and classified individuals in different roles, including the champion. Selection based on $100 \%$ agreement on an individual by multiple nominees. identified different types of champions based on document analysis of recorded discussions over a period of months. Based role identification on definitions from literature.

Lefley (2006) - Spoke to the project appraisal team and reviewed project proposal documentation.

Dong et al. (2007) - Identified by participants and verified through interview with senior manager (appointed project champions).
Negoita et al. (2012) - Considered formally appointed project champions.
Beath (1991) - Champions were initially identified through peer nomination and subsequently verified through individual interviews with the nominees themselves.

Shane (1994) - Individuals were asked about past experiences with overcoming organisational obstacles - champions were identified as individuals with at least one such experience.

Beechler (1996) - Champions not explicitly identified. Results were based on managers' perceptions about championing behaviour in their companies.

Gupta et al. (2006) - Researchers

Matthews et al. (2012) - Nominated and sponsored by CEO and senior management as representatives of their companies.

Klerkx \& Aarts (2013) - Not explicitly mentioned. They appear to be predetermined by the researchers or, at best, identified during their fieldwork; they are not clearly determined via the data.

Andersen \& Mørch (2016) - Users are recognised and appointed based on their participation in the online community. They get appointed after having demonstrated extraordinary skills with the GS software.

\section{Lefley et al (2016) - The survey}

Heng et al. (1999) - Peer nomination Mullins et al. (2008) - Champions by 4 IT consultants familiar with the individuals in the organisations under consideration. A two-step approach was used to finalise the list on the basis of consensus amongst the IT consultants.

Van Laere \& Aggestam (2016) Identified by researchers through observations and an interview. They acknowledge that this is a different approach and justify why they followed it. not explicitly identified. Three items in the survey solicited information from respondents about the presence of a "representative (either the respondent or someone else) who strongly promoted the use of the Internet in meeting client needs". method essentially asked

respondents if they were project champions or not - i.e. self-

nomination. Although the paper offers its own definition (pg 150), this is not actually used to identify or verify the champions.

Finally, lack of rigour in champion identification protocols can also risk succumbing to the pitfall of circular reasoning - the danger of using certain criteria to identify champions initially, and then eliciting those same criteria as characteristics of champions. This was not a common occurrence amongst the reviewed studies, but a couple were vulnerable in this respect.

\section{Research Recommendations:}

xii. All champion research should include a description of the identification procedure followed in the study. Examples of good practice can be found in Howell and Higgins (1990c), Heng et al. (1999) 
and Howell and Boies (2004) who followed a two-step approach of nomination and verification against a definition, and Van Laere and Aggestam (2016) who followed a different, but well-justified approach.

xiii. Ensure that a rigorous procedure is followed to identify champions. As a minimum, researchers should clearly define champions and demonstrate how the definition was operationalised in the field. Researchers should embrace norms of scientific rigour, such as triangulation and elimination of biases, when designing procedures. Good practice suggests a multi-step procedure whereby input from local actors, internal to the organisation, and external researchers can be combined.

xiv. Guard against circular reasoning by ensuring a clear distinction is maintained between the champion identification criteria and the analytical objectives of the study.

The preceding five subsections examined IS champion research from a knowledge generating process perspective as a means to evaluate and interpret cumulative insights. Based on the evidence and the outcomes of our analysis we offer 14 research recommendations; these are proposed as guidelines to maintain or enhance the quality of IS champion research. As such we have answered our first research question about how IS champions are researched, and these process-focused recommendations will be returned to in the concluding section when reflecting on future research priorities. Before that, in the next section, we turn to the second and third research questions around what we know so far about IS champions, potentially distinctive features and what future research directions could be; here we will take a thematic perspective on the progress with IS champion knowledge accumulation.

\section{Thematic Analysis and Findings}

IS champion research was analysed thematically to draw out key conceptualisations, amongst which will be potentially unique features. An inductive process was followed which began with the reviewers reading the whole content of the papers in order to identify broad thematic areas useful for categorizing the empirical focus of papers. Care was taken to ensure the categories were independent of any particular definition or conceptualisation of the notion of 'IS champion'. Coding of these relevant sections was also undertaken using NVivo 10 which helped manage the iterative process of identifying new thematic categories and splitting or combining existing ones. The process was terminated when the independent reviewers reached consensus on a final set of seven thematic areas.

We recognised that such an inductive approach is not a familiar practice in IS systematic literature reviews but selected it for three reasons:

- The aim of the review, particularly the second research question, was to explore the possibility of grouping the IS champion research into sensible thematic areas - such a venture is inductive by its very nature.

- No suitable taxonomy, useful for the purpose of categorizing the empirical work relating to champions, could readily be located - the best way to proceed was to follow a systematic, inductive approach using our set of papers.

- Inductive approaches within SLRs have been acknowledged (e.g. Hammersley, 2002:4) and practised (e.g. Jones, 2004) in other disciplines.

The seven thematic areas - research focal points - that emerged were: i) Champion Origin; ii) their Competencies and Identities; iii) their Roles and Activities; iv) their Relationships and Influence; v) Resource Identification and Mobilisation by champions; vi) their Impact on Projects and Organisations; and vii) Champion Support - the environmental factors conducive for championing.

Following agreement of the themes, the reviewers undertook a final iteration by coding which themes were addressed in each of the 22 papers (Step 6 - data extraction - of the SLR procedure). Themes were formed based on an assessment of three components within each of the sources:

- explicitly-stated research questions or hypotheses,

- the focus of the empirical work, and

- the knowledge contribution embodied by the stated findings.

The summary categorization of papers according to the thematic focus of their research is provided in Figure 4. 


\begin{tabular}{|c|c|c|c|c|c|c|c|c|c|}
\hline Howell \& Higgins (1990a) & & $x$ & $x$ & $x$ & & & & \multirow{3}{*}{$\begin{array}{l}3 \\
3 \\
3\end{array}$} & \\
\hline Howell \& Higgins (1990b) & $x$ & $x$ & & $x$ & & & & & \\
\hline Howell \& Higgins (1990c) & $x$ & $x$ & & $x$ & & & & & \\
\hline Beath (1991) & & & & & $x$ & & $x$ & 2 & \\
\hline Shane (1994) & & $\mathrm{x}$ & $\mathrm{x}$ & $\mathrm{x}$ & & & & 3 & \\
\hline Beechler (1996) & & $x$ & $x$ & $x$ & & & & 3 & \\
\hline Heng et al (1999) & & $x$ & & & & & & 1 & \\
\hline Howell \& Shea (2001) & & $\mathrm{x}$ & $x$ & & & $\mathrm{x}$ & & 3 & \\
\hline Esteves \& Pastor (2002) & $x$ & & $\mathrm{x}$ & & & $\mathrm{x}$ & & 3 & \\
\hline Howell \& Boies (2004) & $x$ & $x$ & $\mathrm{x}$ & $\mathrm{x}$ & & & & 4 & \\
\hline Gupta et al (2006) & & & $x$ & $x$ & & & & 2 & \\
\hline Lefley (2006) & & & $x$ & $x$ & & $x$ & & 3 & \\
\hline Dong et al (2007) & & & & & & $x$ & & 1 & \\
\hline Mullins et al (2008) & $x$ & $x$ & $x$ & & & $\mathrm{x}$ & & 4 & Empirical Focus \\
\hline Kelley \& Lee (2010) & & & & & & & $x$ & 1 & of Source \\
\hline Kamal (2010) & & & $x$ & & & & & 1 & Innovation \\
\hline Negoita et al (2012) & $x$ & & & $\mathrm{x}$ & $x$ & & & 3 & Information \\
\hline Matthews et al (2012) & & & $x$ & & & & $x$ & 2 & Systems \\
\hline Klerkx \& Aarts (2013) & & & $x$ & $x$ & & & & 2 & \\
\hline Andersen \& Mørch (2016) & & & $x$ & & & & & 1 & \\
\hline Lefley et al (2016) & & & & $x$ & & $x$ & & 2 & \\
\hline Van Laere \& Aggestam (2016) & & & $x$ & $x$ & & & & 2 & \\
\hline TOTAL TIMES RESEARCHED: & 6 & 9 & 14 & 12 & 2 & 6 & 3 & & \\
\hline
\end{tabular}

Figure 4. Classification of Sources According to the Thematic Focus of their Research

Figure 4 reveals the varying levels of research attention paid to different aspects of championing in the reviewed literature. On the one hand, studies investigating champions' competencies and identities, relationships and influence tactics, and roles and activities are relatively common in this collection of sources. On the other hand, only six studies explicitly investigated the impact of champions, and in only one case was this the core focus of the paper. Yet it is a rarely-disputed claim that champions have a positive impact; and potential negative impact is an issue that would be of strategic interest to organisations. Only three studies provide insights into the support needs of champions; another important consideration for practitioners. While much is said - speculatively - in the literature about champions and resources, only two of the reviewed studies explicitly researched the resource identification and mobilisation theme. These lacunae clearly provide gaps that future research might fill.

One can also read across Figure 4to note that only five of the 22 studies focussed on a single theme. This might not be unexpected - research on champions is still at a relatively formative stage (albeit with some small sense of acceleration towards the end of the period under review). As such it may be somewhat broader brush than in a more mature research field, where increasing specialisation of thematic focus might be anticipated. 
Key conceptualisations of IS champions will be described and analysed for each of the thematic areas in the sub-sections following (SLR Step 7). Identified knowledge gaps will subsequently be summarized as research directions associated with each thematic area. A set of potential IS champion distinctive features with implied research priorities will be aggregated in the concluding section.

\subsection{Champion Origin}

This theme focuses on the genesis of champions - where do they come from and how do they originate? Few studies explicitly addressed this and because of this scarcity and their heterogeneity of sub-topic, this theme still represents an important gap in conceptualisation of champions that future work needs to address.

Understanding research to date will be an important foundation for such future work, and the main concepts about champion origin were contributed by Howell and Higgins (1990b; 1990c). They proposed that some individuals are predisposed to champion behaviour on the basis of their personality traits, and could be identified using psychological testing. Both they and Beath (1991) accept that - while champions may emerge spontaneously - context shapes this process. However, studies are not in agreement about how context shapes champion emergence: the earlier studies by Howell and Higgins (1990b; 1990c) and Beath (1991) pointed to organisations with many barriers to innovation as a favourable context, while Mullins et al. (2008) found that the need to overcome organisational resistance is less important in champion emergence than was previously thought. Slightly more light is shed on this by Howell and Boies (2004) who found that the emergence of champions can be linked to early involvement during the idea generation stage of a new innovation.

This may be read in a passive mode: for example with weak organisational and technological constraints encouraging the emergence of champions. But it is also seen to have interventionist implications: Howell and Higgins propose development of champions through transformational leadership training; Beath recommends use of 'greenhouse' or 'incubator' services in the organisation which can nurture potential champions and provide them with resources and freedom from constraints.

Others see the origin of champions less in individuals and more within particular organisational roles. One conceptualization perceives champions deriving internally and mainly from senior-level project sponsor roles; unlike the personality-based argument, champions are understood to emerge from positions of authority (Esteves and Pastor, 2002; Negoita et al., 2012). Variants of this see champions emerging from a wider variety of managerial roles (Dong et al., 2007) or as appointed rather than originating from a more organic route (Kamal, 2010). The latter sees those appointments as best made on the basis of a mix of domain knowledge and expertise as well as personality-based factors (ibit). Finally, an interactive perspective posits that championing is catalysed within the informal but intensive collaboration between people working on the same initiative (Van Laere and Aggestam, 2016).

From these different views, two axes can be derived:

- Born vs. made: some authors argue that becoming a champion is the result of an innate predisposition. While context and external interventions may impact the likelihood that this predisposition is expressed in champion behaviour, it does not alter that predisposition. The key task for organisations, therefore, is identification of those who have a champion's profile. Others, however, argue that (almost) anyone can become a champion through appropriate development and training: these, rather than profiling exercises, thus become the focus of organisational intervention.

- Emergent vs. appointed: some authors see champions as naturally emerging within any project or situation of innovation. These individuals take an interest in a particular cause and then begin to champion it. Organisations may affect this via general contextual interventions, but they would not get directly involved at the level of the individual. Others, though, argue that one needs to plan the presence of champions: individuals must be identified, sometimes explicitly assigned the role of champion, before championing can begin.

\section{Future Research Directions:}

i. Studies that explicitly focus on the origins of champions are scarce, so simply conducting research to understand from where and how they emerge would be valuable. The two axes above have been induced, but the reviewed literature to date has not explicitly engaged with these, so it would be helpful to set these axes as focal research questions. These would subject to empirical testing the 
questions of whether IS champions are born or made, emergent or appointed, and would draw practical recommendations for organisations from the results.

ii. The specific practicalities also need investigation in future: If champions are to be identified, what profiling tools are most effective? If training is to be given in order to cultivate champions, what should be its content? If champions are to be appointed, to what formal role should that appointment be?

iii. There are further axes as yet unexplored; such as an internal vs. external axis that would ask where champions originate in relation to organisational boundaries: for example, can external actors be brought in to act as champions?

\subsection{Champions' Competencies and Identities}

This theme considers the characteristics of champions; both their human capital or competencies - skills, attitudes, knowledge; and also their identities - who do they see themselves, and who do others see them, as being? The practical value of such knowledge of champions is that it assists in recognizing, developing and supporting them. In so doing the success of IS projects could potentially be improved.

Converging ideas about champion characteristics can be identified: they are innovative and creative individuals (Howell and Higins, 1990b; Heng et al., 1999; Mullins et al., 2008); they are often transformational leaders (Howell and Higgins, 1990a; 1990b; Dong et al., 2007); they are enthusiastic individuals with dynamic personalities (Howell and Higgins, 1990b; Kamal, 2010); they are discerning and perceive their role in the organisation more broadly and strategically than non-champions, gaining an indepth understanding of organisational context (Howell and Boies, 2004; Mullins et al., 2008); they have 'deviant' preferences and display dissatisfaction with the status quo (Howell and Higgins, 1990c; Shane, 1994; Mullins et al., 2008); they have extensive and diverse career experiences (Howell and Higgins, 1990a; 1990c; Gupta et al., 2006; Kamal, 2010).

Some authors add more depth to this with a contingent perspective, seeing the characteristics of champions varying - or needing to vary - dependent on the context in which they operate (Beechler, 1996; Kamal, 2010). For example, there might be variations depending on which end of the emergent vs. appointed axis prevails. Where champions are not formally appointed and thus their efficacy is not based on delegated authority, noted characteristics include: a propensity to take risks (Howell and Higgins, 1990b; Shane, 1994), an optimistic outlook about the future (Howell and Higgins, 1990a; 1990b), and a preference for using people as sources of information in environmental scanning (Howell and Shea, 2001; Howell and Boies, 2004).

Conversely, in situations where champions are formally appointed, they are often senior managers in positions of authority (Heng et al., 1999; Dong et al., 2007); they may accept rather than oppose formal organisational structures and procedures (though still prefer to be pragmatic by simplifying planning activities) (Shane, 1994; Heng et al., 1999); and there is an emphasis on their possession of expert domain knowledge in relation to the technology or system which they promote (Heng et al., 1999; Kamal, 2010; Andersen \& Mørch, 2016). However, these are mainly associations of characteristics and the emergent vs. appointed axis offered earlier, rather than those of the authors. Hence, while the notion of contingency of characteristics has support, the specific nature of that contingency has not been fleshed out.

\section{Future Research Directions:}

iv. In part, the suggested research directions here follow on from those on champion origins: looking for ways to unify the disparate characterisations given in the different papers, and understanding the practical implications for identifying and developing champions (in turn, overlapping with issues of champion support).

v. The characterisation to date has tended to cluster around a relatively narrow range of characteristics, leaving some much bigger questions - also related to champion origins unanswered: for instance, are champions more often men or women, young or old? And do these major differences betoken different types of champion profile?

vi. How are IS champions different from other types of champions? For example, do they require technical competency and, if so, of what type? Only one study - Heng et al (1999) - touches on this, showing ten IT champions to be a mix of technically and non-technically qualified. But this tells us relatively little since qualification and expertise are two different things: champions could be selftaught technology enthusiasts (e.g. Andersen \& Mørch, 2016). 
vii. As noted, the contingency question remains open: rather than seeking a one-size-fits-all profile, it seems likely champion profiles must to some extent match their situations. But which components of context relate to which champion competencies?

viii. Related to champions' identities, a few important questions come to mind: what are the motivating factors of champions that influence their decisions when promoting IS innovations? To what extent are these motivations aligned with those of the organisation or the project? Better understanding champion motivations and identities will assist champion identification, but the literature also points to the possibility of developing different types of motivations that might be useful to support champions (Barba-Sánchez and Atienza-Sahuquillo, 2012).

\subsection{Roles and Activities}

This thematic area focuses on what champions do within organisations and how they do it. As noted above, an important component of what champions do is the identification and mobilisation of resources, and building relationships with, and influencing others: for example Gupta et al. (2006) and Lefley (2006) mainly discuss these issues in their coverage of champion roles. In this sub-section the aim is to synthesise the broader spectrum of work on champion roles and activities within the organisational context.

Some of the findings here can be related to particular stages of projects. Beechler (1996), Howell and Boies (2004) and Lefley (2006) discuss champion activities in the early stages of projects. The former two papers find that champions are no better than non-champions at generating ideas but that they will identify viable ideas - their own or others - for which they then become enthusiastic supporters, seeing them through to concrete innovations. This involves activity throughout the project lifecycle, including active participation in implementation (Howell and Shea, 2001; Gupta et al., 2006; Kamal, 2010; Andersen \& Mørch, 2016).

In supporting the process of IS innovation, champions have tended to play a linking role between the innovation and the wider organisational context. In one sense they are a lens for understanding innovations more strategically, in the light of those innovations' contribution to key organisational outcomes and values (Howell and Boies, 2004; Matthews et al., 2012; Andersen and Mørch, 2016). As discussed more below, they are a channel that gathers external resources and support for the innovation (Shane, 1994; Kamal, 2010). But they are also a buffer, providing autonomy for the innovation and those working on it from organisational, hierarchical systems and procedures (for example by imposing only loose monitoring systems), thus creating a space within which others can be productive and find innovative and creative solutions to problems (Shane, 1994; Beechler, 1996; Van Laere and Aggestam, 2016). They also work with that team - sometimes formally leading but more often finding ways to build consensus and a sense of unity. And their view of the restrictions imposed by the wider organisation may lead them to encourage and facilitate broader change (ibid.).

We can also extract a slightly different perspective from the literature, relating to the almost universal claim that champions are important. But what is it they do which is particularly important? Three assessments are offered:

- First, that champions' importance comes from their seniority and position in the organisation, which allows them to secure required resources, engage with top managers, and facilitate the organisational change necessary when new technologies are adopted internally (Esteves and Pastor, 2002).

- Second, that champions are important because they cast compelling visions - transcending individual interests - that cultivate favourable beliefs about the innovation among potential users (Dong et al, 2007).

- Third, that the importance of champions comes from their ability to advance the adoption of innovations within organisations (Mullins et al, 2008); for example, by bridging different stakeholder groups inside and outside the organisation thereby advancing the innovation (Andersen and Mørch, 2016).

Note that importance (the criticality of contribution) is not the same as impact (the consequences of contribution), which is discussed below.

Overall, we might conclude that the role and activities of champions centre on vision - an orientation to results, including organisationally-strategic results; on harnessing resources and support; on creating an environment that is conducive for advance towards the overall goal; and on seeing innovations through to adoption. Although they must have the ability to assess the technical ideas that arise and support the 
technical staff working on the IS innovation, there are otherwise few signs here of a need to apply technical, domain-based expert knowledge and skills (one of the issues raised in the previous sub-section).

\section{Future Research Directions:}

ix. The focus of IS champion studies has typically been the individual, but one can see that what matters is the role of the individual within an organisational context, so more research needs to undertake organisational-level analysis of champions (a research gap already argued by some (Mullins et al., 2008; Van Laere and Aggestam, 2016)).

$x$. This focus on the individual has also tended to obscure the fact that there may be multiple champions operating in the same IS innovation arena. Three studies (Gupta et al., 2006; Klerkx and Aarts, 2013; Van Laere and Aggestam, 2016) have broached this issue and identified different roles played by different champions, but further work is needed to flesh out what those roles are, perhaps in the form of a taxonomy of IS champions, and in understanding how teams of champions work together (or fail to do so!).

xi. The theme of contingency needs to be expanded in future work: researching how the role of an IS champion may differ at different stages of the innovation lifecycle; researching the different roles required for different scales of IS innovation, from one introduced into a single organisational subsection, up to those based on inter-organisational and (inter-)national roll-out; and researching the role of champions in formalised IS project structures vs. situations that have not been formalised.

xii. Related to this last point, more understanding is needed about the formal vs. informal roles of champions; perhaps particularly the ways in which champions sometimes need to ignore or subvert formal procedures.

xiii. Research into roles has tended to remain bounded to a typical project cycle. But it will be valuable to step outside this and ask, for example, what champions do as and when they exit from an IS project; and what they do in the gaps between championing. Taking an even greater longitudinal approach, do they tend to be one-time or multiple champions, and do they tend to be parallel or serial champions?

\subsection{Relationships and Influence}

A primary and distinguishing feature of champions is their ability to enrol others into their vision-based endeavours. The importance of relationships and influence tactics is evidenced by the volume and frequency of research attention in the selected sources; twelve studies explicitly attended to some aspect of this theme (see Figure 4).

From the literature, we find that champions draw on their personal networks to advance the IS innovation to which they commit (Howell and Shea, 2001; Howell and Boies, 2004; Gupta et al., 2006); and while they may draw on different parts of this network at different points in a project, they actively work all the time to expand that network (ibid.). For some, the focus is on network- and relationship-building inside the organisation, while others concentrate on external relationships (ibid.).

Research has mostly analysed champions' relationship orientations within the context of their personal networks where they are somehow perceived as 'single heroes'. However, the importance to championing of different relational networks has recently been recognised (Klerkx and Aarts, 2013; Van Laere and Aggestam, 2016): relationships and collaboration between champions - champion networks - are important, as are collectives within the organisation that work together to champion an innovation.

Within these relationships, champions use influencing tactics at high frequency, and they have a large repertoire of such tactics (Howell and Higgins, 1990a; 1990b; 1990c; Beechler, 1996). There is a preference for informal methods of persuasion (Shane, 1994; Howell and Boies, 2004) such as the articulation of a compelling vision and expressions of confidence in the ability of others to participate in the innovation (Howell and Higgins, 1990b). That vision may seek to link problems: dissatisfaction with the status quo, and solutions: the strategic benefits of the new technology (Lefley 2006; Mullins et al., 2008; Lefley et al. 2016). An alternative perspective on this is to say that champions tend not to use transactional-style influencing tactics with personal rewards (an exchange between champions and others where the former offer something in exchange for the latter to do a certain task), but prefer transformational-style tactics (a champion motivating and inspiring someone else resulting in a response where the goal of the collective is prioritised over the individual's personal objectives) through coalition building, reasoning, drawing on higher 
authority and assertiveness (Howell and Higgins, 1990c; Shane, 1994). Their ability to successfully practice these tactics is shaped by factors including the perceived nature of the champion (organisational position, experience, trustworthiness) and the type of technology under consideration (Negoita et al., 2012).

\section{Future Research Directions:}

xiv. As ever, the issue of contingency is raised: the need for research into the different types of relationships and different tactics of influence used - in different situations; by different types of champions; and with different project stakeholders (executives, managers, technical staff, etc.).

$\mathrm{xv}$. There is little sense of prioritisation as yet: which relationships matter most, and which influencing tactics work best?

xvi. Following the discussion about multiple champions, one can see that research to date has been about interactions between champions and "others". So a gap remains in researching networks of champions, to understand how they collaborate or otherwise interact with each other.

xvii. The target population that requires change and its links with the different relationship orientations and influence tactics of champions require better understanding.

\subsection{Resource Identification and Mobilisation}

Champions are often implicitly associated with identifying and obtaining resources in order to advance their IS projects through critical stages, yet only two of the reviewed studies looked at this as an a priori topic. A notable differentiation can be drawn between resource types: information and technical resources are critical material resources for champions (Beath, 1991) - this conceivably an IS champion specificity; political support and social capital are non-material resources of notable importance to champions' initiatives in identifying and unlocking various kinds of resources for the IS innovation to succeed (Beath, 1991; Negoita et al., 2012).

Some of the other papers provide some passing insights on champions' resource orientation. This may be just to reinforce the general message that champions are seen to bear responsibility for obtaining resources for projects (Esteves and Pastor, 2002; Heng et al, 1999). But there are a few details: champions utilise their social capital, influence and relationships to acquire resources (Shane,1994; Negoita et al., 2012). And the sense of improvisation and informality seen in other themes is also present here: for example, Howell and Boies (2004) use the analogy of scavengers to explain how champions covertly identify and mobilise resources.

The critical nature of non-material resources is also reinforced, with champions said to secure the 'support' (Shane, 1990), 'motivation' (Howell and Higgins, 1990c) and 'enthusiasm' (Howell and Boies, 2005) of other stakeholders, such as both more senior and more junior staff. This and earlier findings thus suggest a need to expand Roure's definition offered earlier beyond just resource-seeking from top management.

\section{Future Research Directions:}

xviii. The limited explicit research attention to this aspect of championing is offered as both a gap in the literature and a necessary area for future research.

xix. One approach would be to combine a focus on resource identification and mobilisation with another thematic area such as relationships and influence: What relationships and what influencing tactics do champions use in obtaining resources? This could also be investigated together with champion impact, for example: How does a champion's ability to mobilise resources impact the outcome of an IS project?

xx. It is also important to better understand if and how the roles of champions differ in contexts with variations in types and availability of required resources.

\subsection{Impact on Projects and Organisations}

Researching the impact of champions, let alone any specific aspect of champions, on IS innovations is difficult because of the problem of attribution - how to isolate those impacts just related to champions within the myriad of factors at play - and the problem that at least some of the measures involved would be qualitative and potentially subjective. These challenges may explain why relatively few - only six - of the reviewed papers even partly covered this theme. This may also relate to definitions of champions, with their 
inherent assumption that the impact of champions is to drive their IS innovation forward to successful implementation.

A very helpful corrective to this is to differentiate between champion impact during the early stages of the project as opposed to involvement later on (Lefley, 2006; Lefley et al., 2016). Here the argument is that champions impact projects by driving them forward in the early stages, overcoming objections by lowering perceptions of risk and raising perceptions of strategic benefits. But this has a negative overall impact if, in reality, the project was not beneficial for the organisation. The analogy one might use is of the champion as turbocharger: making the IS innovation reach its destination more quickly but not necessarily driving in the right direction.

More generally, though, papers present evidence of positive impact with Mullins et al (2008) finding Internet adoption and use greater where champions are involved. Other evidence is a little eclectic. For example, there are indications of a positive impact of champions on user technological beliefs (Dong et al., 2007); something which is at some distance removed from impacts such as project or organisational success. And Esteves and Pastor (2002) address only the 'mirror-image': offering circumstantial evidence that departure of a champion can have a negative impact on ERP projects. Only Howell and Shea (2001) address this theme broadly and directly via a longitudinal study which found that championing behaviour positively predicted the outcomes of 47 product innovation projects.

\section{Future Research Directions:}

xxi. With only one paper directly addressing this theme, there is a need for more research; particularly given that this is the 'bottom line' of champions. A descriptive interest may arise from their mere existence, but a prescriptive interest arises from the promise that champions have a positive impact and improve success rates.

xxii. 'Improve success rates of what?' is another question. One can see that research is required based on a two-level analysis; looking at champions' impact on IS projects but also on the wider organisation. (And of course, one could turn this around to look at the impact of organisations' activities on champions themselves; and the impact they have on other key individuals around them.)

xxiii. Beyond the direct connection to impact, one also needs to know what differential impact on IS innovations different elements from the themes have; such as different types of champions, and different activities of champions, at different times during a project.

xxiv. The negative impacts of champions are under-researched. Developing the turbocharger analogy, (how) may champions end up driving IS innovations in the wrong direction?

\subsection{Champion Support}

We have seen that champions are influenced by the context in which they operate (Kamal, 2010; Beechler, 1996), so what does this mean for conscious attempts to support them? Some of the literature is nonspecific; for example, merely advocating general changes to the organisational context in order to encourage champions to emerge (Shane, 1994). Other recommendations are narrowly-specific: e.g. that transformational leadership training will help encourage emergence of champions (Dong et al., 2007; Howell and Higgins, 1990b). Beyond emergence, champions can benefit from support while enacting their main role. Three areas in which champions need and value support are: i) information that can be used as persuasive evidence of their vision for using the innovation; ii) flexibility in the implementation process; and iii) political support for their vision (Beath, 1991).

Two final papers provide some contingent insight, though mixing the prescriptive and the descriptive. Support may vary by type of project: those closely related to current organisational operations require empowerment and sponsorship; those that strategically diverge from that direction require more directive control from senior staff (Kelley and Lee, 2010). Support may also vary by size of organisation: in larger organisations, champions are often some way down the hierarchy and do not receive direct support from top managers; in smaller organisations, that direct connection is more easily made (Matthews et al., 2012).

The differences in support have a bearing on the champion's ability to bring about change, whether it is organisational change or social change. Champion support, in the narrowest sense means assisting them in their typical roles and activities outlined earlier. But taking a broader and interventionist perspective would suggest creating an environment that is supportive of championing - for champions to either emerge or be 
recognised and appointed and further developed throughout the duration of an initiative; this would require a more in-depth and nuanced understanding of their support needs than is currently available.

\section{Future Research Directions:}

xxv. Contributions in this section draw largely from studies at the emergent end of the continuum. So more work is needed on the particular support requirements of formally-appointed IS champions.

xxvi. While acknowledging their general relevance, the work has not investigated the role of environmental factors - organisational culture, organisational structure, systems of governance, systems of compensation - on champions.

Research needs to push beyond mere presence/absence of support components, to understand the specific effect these have on the actions of champions and, in turn, on the performance of IS innovations.

\section{Discussion and Conclusions}

We commenced with the premise that champions play a key role in the success of IS projects and that understanding their contributions is particularly important given the dismal history of poor project performance. However, IS champion research lacks progressive coherence and knowledge building: evidence of the extent of this problem as well as possible causes have been offered throughout the paper. In a general sense, this ineffective knowledge accumulation hampers much needed progress with IS champion research and subsequent improvements to IS practice. More specifically, potential distinctiveness of IS champions has not yet been made visible. In-depth understandings of bespoke IS champion features are needed to enable IS practice to optimise potential benefits to be derived from their involvement. The paper is aimed at this knowledge gap, seeking to be a one-stop foundation and guide for those wishing to research IS champions given the current lack of such a resource. Three contributions will now be briefly outlined.

During the paper introduction it was argued that, in addition to their individual characteristics, IS champion distinctive features could potentially be derived from the organisational contexts they function in and the information/technological innovations they promote. These three aspects have been combined to form a simple classification scheme to propose the following eight IS champion distinctive features, presented in Figure 5.

We have drawn the Figure 5 IS champion distinctive features from the thematic analysis and offer it as our first contribution. This was mainly done through triangulation of findings, but also took research rigour of the individual articles into account. Whilst more potential distinctives can be added to the list, we felt most confident with the strength of supporting evidence about these eight features. Importantly, by referring to these features as distinctive we do not suggest they are all unique to IS champions - it is indeed likely that some of these are also characteristics of champions in other domains. However, the combination of these distinctives is likely unique to IS champions. Practically speaking, these are features that could be used to recognise IS champions .

In terms of individual characteristics - independent of organisational context or focal technology - we found strong support for IS champions as innovative, creative and dynamic individuals. A single technologyspecific feature identified is their depth of knowledge about the focal information technology. Three distinctive features were identified at the intersection of individual and organisational factors; these relate to how they influence others inside and external to the organisation, their understanding of the organisational strategy, and their preference to work collaboratively instead of on their own. Elements of all three factors were combined to forward three final distinctives; these relate to their diverse career experiences, their deliberate linking of organisational strategy and the IS innovation as a key championing task, and their involvement in all phases of the innovation process and subsequent technology diffusion.

From a research perspective, a set of distinctive features such as these will assist to prioritise and focus future IS champion research with positive knock-on effects on IS practice - this will be returned to shortly when outlining our third contribution which is an IS champion research agenda. From the perspective of organisational practices, the rationale for seeking IS champion-specific knowledge is to more effectively identify, develop, deploy and support these key individuals; in so doing, this knowledge could contribute to IS innovation success and consequently benefit organisations. 


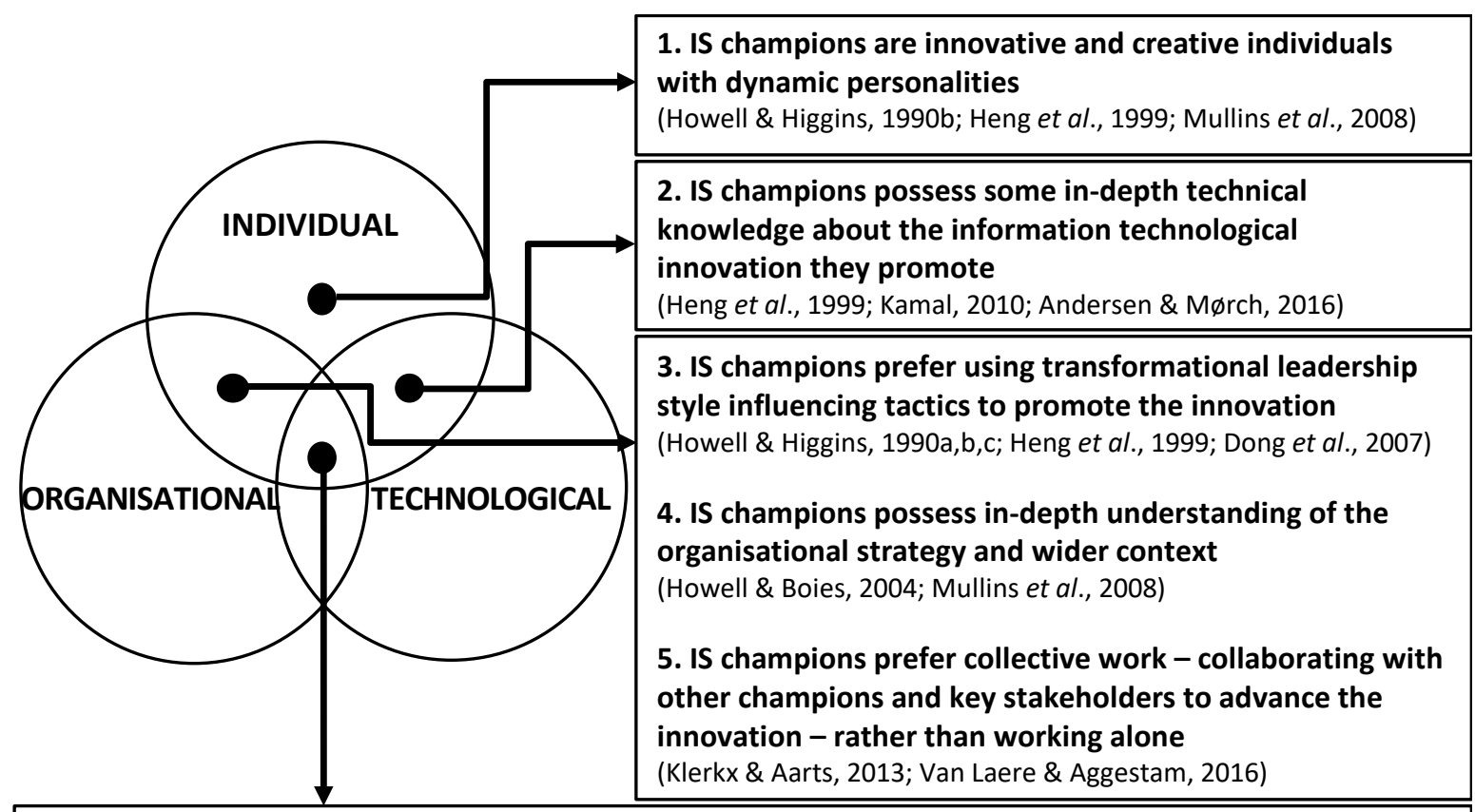

6. IS champions have extensive and diverse career experiences, with different organisations and technologies, which they draw on in order to promote the focal innovation (Howell \& Higgins, 1990a; 1990c; Gupta et al., 2006; Kamal, 2010)

7. A key task IS champions undertake is to translate, for all stakeholders, between the focal innovation, organisational strategy and wider context in order to promote the focal innovation (Howell \& Boies, 2004; Matthews et al., 2012; Andersen \& Mørch, 2016)

8. IS champions focus strategically on the results of successful innovation by advancing both the innovation itself - promoting its progress through the innovation process stages - and the effective diffusion of the technological innovation

(Howell \& Shea, 2001; Gupta et al., 2006; Kamal, 2010; Andersen \& Mørch, 2016)

Figure 5. Propositions about IS Champion Distinctive Features

Our second contribution is to refine Roure's (1999) definition by factoring in the IS champion distinctive factors outlined above. Three amendments are proposed. First, we argued early on in the paper that 'innovation' in Roure's definition could be made more specific by referring to 'socio-technical innovation' we propose this will more accurately reflect the nature of IS and therefore make the definition more precise. Second, following from the socio-technical nature of IS innovations, we propose the definition of IS champions should more accurately capture the non-technical aspects that are seminal to successful IS innovation, namely the assimilation thereof into the organisation; 'critical stages' in Roure's definition could be made more specific by referring to 'critical innovation and diffusion stages'. Third, it became evident from the thematic analysis that IS champions are not only targeting top management for support and resources, but involve all relevant organisation stakeholders and even external stakeholders, whose support might contribute to the success of the innovation. As such, 'top management' in Roure's definition could be made more accurate by referring to 'all stakeholders'. We combine these ideas to forward our second contribution - an improved and more evidence-based definition for IS champions:

any individual who makes a decisive contribution to the socio-technical innovation by actively and enthusiastically promoting its progress through critical innovation and diffusion stages in order to obtain resources and active support from all stakeholders

The first two contributions are therefore aimed at the knowledge gap about the distinctiveness of IS champions. As such they cut across the three secondary questions posed at the outset of the paper. We now briefly return to those questions individually in order to conclude with an IS champion research agenda as our third contribution. 
To start with, a perspective on the process of researching IS champions was brought into focus by asking: How are IS champions researched and by whom? This process angle was needed to obtain a better understanding of the reliability and rigour of knowledge created thus far. Here our analysis evidenced the multiple disciplines with an interest in IS champions. The unique perspectives and competencies that researchers from diverse disciplines bring to bear were particularly evident from the diversity of theories that were identified in the collection of reviewed sources. However, this diversity came at a price: little incremental knowledge accumulation and theory building occur as a result of the relatively isolated manner in which studies are performed.

In contrast to this theoretical diversity, we found a lack of variety of research philosophies: a positivist monoculturalism is prevalent amongst the reviewed studies. Here we point out opportunities to enrich and advance IS champion knowledge by increasing diversity; the value of alternative philosophies such as interpretivism, critical social theory and critical realism was explicated.

We surmise that authors tend to bring research approaches and practices from their home disciplines and establish links back to those sources, but omit meaningful engagement with existing IS champion work, including with sources originating from other disciplines. The prevalence of this approach to IS champion research is akin to reinventing the wheel with every new research project; almost every study starts from scratch thereby forfeiting the benefits of building on prior work. Our 14 recommendations about champion research approaches and practices are offered towards unlocking the full potential of multi- and interdisciplinary study of IS champions, including the discrete features that we have brought to the fore in this paper.

A thematic perspective was brought into focus by asking: What has research so far told us about IS champions and what might be their potentially unique characteristics? This is still a challenge: only twentytwo papers from the IS and innovation literature met the review criteria. We thus acknowledge limitations because of this small size in an overall sense, and also in what it has prevented; for example, we were not able to provide a clear sense of changes in ideas over time.

Because of the relative immaturity of research in this field, there is limited depth to the findings; findings which must often be seen as foundations for more critical and analytical insights in future. Even within this small collection, though, there is some sense of continuity and connection - a few later papers in the review cite earlier ones and use their evidence. Howell represents a key node and foundation, co-authoring nearly half of the innovation papers. And all the themes had multiple paper contributions.

Beyond those themes and the Figure 5 distinctive features drawn from it, and at an even-more generalised level, three descriptive constructs cut across the literature and help us refine our sense of who IS champions are and what they do:

1. IS Champions are concerned with Results - they are not distracted by operational issues and shortterm obstacles, but have a strategic vision about successful project outcomes and even beyond.

2. IS Champions are concerned with Relationships - actively engaging with various stakeholders with the purpose of promoting ideas, rallying support and building consensus.

3. IS Champions are concerned with Resources - actively identifying and mobilizing the tangible and intangible resources needed to advance the project.

With this broad conceptualisation of IS champions around results, relationships and resources and the seven thematic areas, the scaffolding is in place for advancing research.

Our third research question asked: What might be the priorities for future research on IS champions? From what we presented so far one might be tempted to answer 'anything and everything' - above we offered 14 recommendations to advance the process of IS champion research and outlined 27 different future research directions, and could have included more. These numbers arise because of the formative nature of the field. Nonetheless, in an attempt to give a clearer sense of future research priorities, we turn to the tri-part criteria often used in judging research quality: rigour, originality and significance (Johnston, 2008; Paul, 2008).

Firstly, actions to improve the rigour in future IS champion research can be prioritised. Whilst we acknowledge the subjective nature of rigour as a value assessment of research quality, we posit that IS champion research can significantly advance in terms of the cross-cutting norms of good research thoroughness, transparency, consistency. Persuasive opportunities revealed in our analysis include:

- Deeper and more meaningful engagement with prior IS champion research in order to optimise the incremental accumulation of knowledge; 
- Being explicit about research design decisions by clarifying the underpinning philosophical assumptions of the study and offering clear justification for methodological decisions, data sources, methods and analytical procedures;

- Demonstrating congruency from start to end in the research value chain - from research philosophy, the role of theory, methodologies, methods and data sources, to the resulting knowledge contributions.

Secondly, future IS champion research should seek to make original contributions of knowledge. Originality, on the one hand, can be accomplished through the adoption of novel and unique research approaches and practices: a range of promising philosophies, theories, research strategies, methodologies and methods has been suggested. Such diversification at the research process-level holds the potential to both strengthen and expand existing IS champion knowledge. On the other hand, originality can be accomplished on the thematic level: many knowledge gaps about IS champions have been shown and channelling research attention in those directions could result in very interesting new insights about champions and their roles in IS projects. New and perhaps more significant IS champion distinctives will be valuable original contributions to aim for.

Thirdly and perhaps most important is the suggestion to prioritise IS champion research that is significant. An obvious starting point would be to focus on explaining and further exploring unique aspects of championing IS innovations; the eight distinctives proposed earlier are offered as significant research themes. IS practise would be more effectively advanced by actioning bespoke IS champion knowledge compared to generic knowledge about championing in other domains - we propose prioritizing a sharpshooter approach over a shotgun approach. Further to this, we have identified a plethora of research opportunities in the penultimate section; many of those could be very interesting, but the anticipated practical impact of gaining such knowledge might not be immediately clear. Guided by the need to directly impact the success of IS projects in practice, we recommend prioritisation of the following five issues:

- Identification and development of champions. While opinions and research about the origin of champions are on-going, it is imperative that effective champions are actually developed. How can potentially-successful IS champions be identified? How can champions be cultivated and developed?

- Champions and results. What exactly are the visions that IS champions hold, and to what extent do they align with the strategic interests of organisations? How important are champions to the bottomline results of the organisations for whom they work?

- Champions and relationships. Which are the most important relationships for IS champions? How do they go about building and maintaining those relationships?

- Champions and resources. Given resource acquisition is central to the work of champions: How do IS champions identify and mobilise resources? What are the implications of the resource-orientation of champions for IS projects and organisations?

- Contingency. How do answers to all the above questions vary: by type of technology, by type of organisation, by type of organisational environment, etc.?

Existing research represents a broad foundation of knowledge, but the most actionable knowledge would draw on the bespoke features of these key individuals. We summarise that rigour, originality and significance should be guiding lights when prioritizing future research on IS champions.

To conclude we return to Donald Schön who recognised the importance and significance of champions:

"Where radical innovation is concerned, the emergence of a champion is required ... the new idea either finds a champion or dies" (1963:84)

Today we might rework his words:

"Where major IS innovation is concerned, the presence of an IS champion is required ... the new IS innovation either finds a champion or dies"

Above all, this is why research into IS champions should advance. 


\section{References}

Andersen, R. \& Mørch, A. I. (2016). Mass Collaboration in Software Product Development Between Developers and Users: Champion as Emergent Role. In CoPDA@ NordiCHI, 14-20.

Appolis, K. \& Alexander, B. (2013). Sustainable m-Governance Strategies for Communities in Tension: Exploring the Role of the Grassroots Champion. CPUT Conference. Cape Peninsula University of Technology.

Bankins, S., Denness, B., Kriz, A. \& Molloy, C. (2017). Innovation Agents in the Public Sector: Applying Champion and Promotor Theory to Explore Innovation in the Australian Public Service. Australian Journal of Public Administration, 76(1), 122-137.

Barba-Sánchez, V. \& Atienza-Sahuquillo, C. (2012). Entrepreneurial Behavior: Impact of Motivation Factors on Decision to Create a New Venture. Investigaciones Europeas de Dirección y Economía de la Empresa, 18(02), 132-138.

Bassellier, G., Benbasat, I. \& Reich, B. (2003). The Influence of Business Managers' IT Competence on Championing IT. Information Systems Research, 14(4), 317-336.

Beath, C. M. (1991). Supporting the Information Technology Champion. MIS Quarterly, 15(3), 355-372.

Beath, C. M. \& Ives, B. (1988). The Information Technology Champion: Aiding and Abetting, Care and Feeding. In: The Twenty-First Annual Hawaii International Conference on Systems Sciences, 1988. IEEE, 115-123.

Becker, J. \& Niehaves, B. (2007). Epistemological Perspectives on IS Research: A Framework for Analysing and Systematizing Epistemological Assumptions. Information Systems Research, 17(2), 197-217.

Beechler, S. (1996). Ware Ware Nihonjin but We're not All Alike: How Japanese Managers Champion Innovation. PhD, Columbia University.

Burrell, G. \& Morgan, G. (1979). Sociological Paradigms and Organizational Analysis. London, UK: Heinemann Educational Publishers.

Calish, I. G. \& Gamache, R. D. (1984). Wizards and Champions: the Kingdom of New Venture Management. Journal of Product Innovation Management, 1(4), 238-241.

Cerpa, N. \& Verner, J. M. (2009). Why did your project fail? Communications of the ACM, 52(12), 130-134.

Chakrabarti, A. K. (1974). The Role of Champion in Product Innovation. California Management Review, 17(2), 58-62.

Chen, W. \& Hirschheim, R. (2004). A Paradigmatic and Methodological Examination of Information Systems Research from 1991 to 2001. Information Systems Research, 14(3), 197-235.

Coakes, E. \& Smith, P. (2007). Developing Communities of Innovation by Identifying Innovation Champions. The Learning Organization, 14(1), 74-85.

Curley, K. F. \& Gremillion, L. L. (1983). The Role of the Champion in DSS Implementation. Information \& Management, 6(4), 203-209.

Dong, L., Sun, H. \& Fang, Y. (2007). Do Perceived Leadership Behaviors Affect User Technology Beliefs? An Examination of the Impact of Project Champions and Direct Managers. Communications of the Association for Information Systems, 19, 655-664.

Dorado, S. \& Vaz, P. (2003). Conveners as champions of collaboration in the public sector: A case from South Africa. Public Administration and Development, 23(2), 141-150.

Dwivedi, Y.K., Wastell, D., Laumer, S., Zinner Henriksen, H., Myers, M. D., Bunker, D., Elbanna, A., Ravishankar, M. N. \& Srivastava, S. C. (2015). Research on Information Systems Failures and Successes: Status Update and Future Directions. Information Systems Frontiers, 17(1), 143-157.

Easterby-Smith, M., Golden-Biddle, K. \& Locke, K. (2008). Working With Pluralism: Determining Quality in Qualitative Research. Organizational Research Methods, 11(3), 419-429.

Esteves, J. \& Pastor, J. A. (2002). Understanding the ERP Project Champion Role and its Criticality. European Conference on Information Systems. Gdańsk, Poland. 
Fischer, W. A., Hamilton, W., McLaughlin, C. P. \& Zmud, R. W. (1986). The Elusive Product Champion. Research Management, 29(3), 13-16.

Fitzgerald, B. \& Howcroft, D. (1998). Competing dichotomies in IS research and possible strategies for resolution. In: Proceedings of the international conference on Information systems, 12/13/1998 1998. Association for Information Systems, 155-164.

Fujii, S. (2017). Product Champion for Successful Innovation: A Review of the Previous Literature and Challenge for the Future. British Journal of Research, 4(22), 1-9.

Goldberg, L. R. (1990). An Alternative "Description of Personality": The Big-Five Factor Structure. Journal of Personality and Social Psychology, 59(6), 1216-1229.

Gregor, S. (2006). The Nature of Theory in Information Systems. MIS Quarterly, 30(3), 611-642.

Gupta, S., Cadeaux, J. \& Dubelaar, C. (2006). Uncovering Multiple Champion Roles in Implementing NewTechnology Ventures. Journal of Business Research, 59(5), 549-563.

Hammersley, M. (2002). Systematic or Unsystematic? Is that the Question?: Some Reflections on the Science, Art, and Politics of Reviewing Research Evidence. Public Health Evidence Steering Group of the Health Development Agency. University of Leicester, UK.

Hastie, S. \& Wojewoda, S. (2015). Standish Group 2015 Chaos Report - Q\&A with Jennifer Lynch [Online]. Available: https://www.infoq.com/articles/standish-chaos-2015 [Accessed 23/08/2016].

Heng, M. S. H., Trauth, E. M. \& Fischer, S. J. (1999). Organisational champions of IT innovation. Accounting, Management and Information Technologies, 9(3), 193-222.

Howell, J. M. (2005). The Right Stuff: Identifying and Developing Effective Champions of Innovation. The Academy of Management Executive, 19(2), 108-119.

Howell, J. M. \& Boies, K. (2004). Champions of technological innovation: The influence of contextual knowledge, role orientation, idea generation, and idea promotion on champion emergence. The Leadership Quarterly, 15(1), 123-143.

Howell, J. M. \& Higgins, C. A. (1990a). Champions of Change: Identifying, Understanding, and Supporting Champions of Technological Innovations. Organizational Dynamics, 19(1), 40-55.

Howell, J. M. \& Higgins, C. A. (1990b). Champions of Technological Innovation. Administrative Science Quarterly, 35(2), 317-341.

Howell, J. M. \& Higgins, C. A. (1990c). Leadership Behaviors, Influence Tactics, and Career Experiences of Champions of Technological Innovation. The Leadership Quarterly, 1(4), 249-264.

Howell, J. M. \& Shea, C. M. (2001). Individual differences, environmental scanning, innovation framing, and champion behavior: key predictors of project performance. Journal of Product Innovation Management, 18(1), 15-27.

Irvine, R. \& Hall, H. (2015). Factors, Frameworks and Theory: A Review of the Information Systems Literature on Success Factors in Project Management. Information Research, 20(3), 1-46.

Jennex, M. E. (2015). Literature Reviews and the Review Process: An Editor-in-Chief's Perspective. Communications of the Association for Information Systems, 36, 1-4.

Johnston, R. (2008). On Structuring Subjective Judgements: Originality, Significance and Rigour in RAE2008. Higher Education Quarterly, 62(1-2), 120-147.

Jones, K. (2004). Mission Drift in Qualitative Research, or Moving Toward a Systematic Review of Qualitative Studies, Moving Back to a More Systematic Narrative Review. Qualitative Report, 9(1), 95-112.

Kamal, M. (2010). Investigating the Role of Project Champions in e- Government Integration Initiatives in Local Government Domain. Americas Conference on Information Systems (AMCIS).

Kelley, D. \& Lee, H. (2010). Managing Innovation Champions: The Impact of Project Characteristics on the Direct Manager Role. Journal of Product Innovation Management, 27(7), 1007-1019.

Khabsa, M. \& Giles, C. L. (2014). The Number of Scholarly Documents on the Public Web. PLoS ONE, 9(5), $1-6$. 
Klerkx, L. \& Aarts, N. (2013). The Interaction of Multiple Champions in Orchestrating Innovation Networks: Conflicts and Complementarities. Technovation, 33(6-7), 193-210.

Levy, Y. \& Ellis, T. J. (2006). A Systems Approach to Conduct an Effective Literature Review in Support of Information Systems Research. Informing science, 9, 181-212.

Lefley, F. (2006). Can a project champion bias project selection and, if so, how can we avoid it? Management Research News, 29(4), 174-183.

Lefley, F., Hynek, J. \& Janeček, V. (2016). Formal Assessments, Teams and Influence of a Project Champion in the Selection of ICT Projects: A Czech Republic and UK Study. Prague Economic Papers, 25(2), 143-159.

Lichtenthaler, U. \& Ernst, H. (2009). The Role of Champions in the External Commercialization of Knowledge*. Journal of Product Innovation Management, 26(4), 371-387.

Maidique, M. A. (1980). Entrepreneurs, Champions, and Technological Innovation. Sloan Management Review, 21(2), 59-76.

Markham, S. K. \& Aiman-Smith, L. (2001). Products Champions: Truths, Myths, And Management. Research Technology Management, 44(3), 44-50.

Markus, M. L., \& Benjamin, R. I. (1996). Change agentry-the next IS frontier. MIS Quarterly, 385-407.

Matthews, J. H., Bucolo, S. \& Wrigley, C. (2012). Challenges and Opportunities in the Journey of the DesignLed Innovation Champions. In: Bohemia, E., Liedtka, J. \& Rieple, A. (eds.) DMI 2012 International Research Conference. Boston, MA, USA: DMI.

McManus, J. \& Wood-Harper, T. (2007). Understanding the Sources of Information Systems Project Failure. Management Services, 51(3), 38.

Mingers, J. (2004a). Re-establishing the Real: Critical Realism and Information Systems. In: Mingers, J. \& Willcocks, L. (eds.) Social Theory and Philosophy for Information Systems. Chichester, UK: John Wiley \&amp; Sons Ltd.

Mingers, J. (2004b). Real-izing Information Systems: Critical Realism as an Underpinning Philosophy for Information Systems. Information and Organization, 14(2), 87-103.

Mohi Uddin, A. (2000). Champions of Collaboration in Technological Innovation Processes. Proceedings of the Annual Conference of the Japan Society for Science Policy and Research Management, 15, 4851.

Molloy, C. \& Kriz, A. (2012). Investigating the Behaviours, Impact and Motivations of Innovation Champions. Australia and New Zeeland Acedemy of Management (ANZAM 2012). Perth.

Monod, E. (2003). A Copernican Revolution in IS: Using Kant's Critique of Pure Reason for Describing Epistemological Trends in IS. In: Americas Conference on Information Systems (AMCIS), 2003. AIS Electronic Library, 2719-2724.

Mullins, M. E., Kozlowski, S. W. J., Schmitt, N. \& Howell, A. W. (2008). The Role of the Idea Champion in Innovation: The Case of the Internet in the mid-1990s. Computers in Human Behavior, 24(2), 451467.

Negoita, B., Rahrovani, Y., Lapointe, L., Pinsonneault, A. \& Mirza, M. (2012). IT Champions as Agents of Change: a Social Capital Perspective. In: ICIS 2012 Proceedings.

Okoli, C. \& Schabram, K. (2010). A Guide to Conducting a Systematic Literature Review of Information Systems Research. Sprouts: Working Papers on Information Systems, 10(26), 1-49.

Orlikowski, W. J., Baroudi \& J, J. (1991). Studying Information Technology in Organizations: Research Approaches and Assumptions. Information Systems Research, 2(1), 1-28.

Palvia, P., Leary, D., Mao, E., Midha, V., Pinjani, P. \& Salam, A. F. (2004). Research Methodologies in MIS: an Update. Communications of the Association for Information Systems, 14, 526-542.

Paul, R. J. (2008). Measuring Research Quality: the United Kingdom Government's Research Assessment Exercise. European Journal of Information Systems, 17(4), 324-329. 
Renken, J. C. \& Heeks, R. B. (2013). Conceptualising ICT4D Project Champions. The Sixth International Conference on Information and Communications Technologies and Development. Cape Town, South Africa.

Renken, J. C. \& Heeks, R. B. (2014). Champions of Information System Innovations: Thematic Analysis and Future Research Agenda. UK Academy for Information Systems (UKAIS) International Conference. Oxford, UK.

Roberts, E. B. (1968). Entrepreneurship and Technology: a Basic Study of Innovators; How to Keep and Capitalize on their Talents. Research Management, 11(4), 249-266.

Rogers, E. M. (2003). Diffusion of Innovations. 5 Ed, New York: The Free Press.

Roure, L. (1999). Cultural Differences in Product Champions Characteristics: A comparison of France and Germany. Mars: Centre de Recherche DMSP.

Sahay, S. \& Walsham, G. (1995). Information Technology in Developing Countries: A Need For Theory Building. Information Technology for Development, 6(3-4), 111-124.

Sarkar, M. B., Butler, B. \& Steinfield, C. (1995). Intermediaries and Cybermediaries: A Continuing Role for Mediating Players in the Electronic Marketplace. Journal of Computer-Mediated Communication, 1(3), 1-14.

Schmidt, R., Lyytinen, K., Keil, M. \& Cule, P. (2001). Identifying Software Project Risks: An International Delphi Study. Journal of Management Information Systems, 17(4), 5-36.

Sergeeva, N. (2016). What Makes an "Innovation Champion"? European Journal of Innovation Management, 19(1), 72-89.

Schön, D. A. (1963). Champions for Radical New Inventions. Harvard Business Review, 41(2), 77-86.

Sen, A. (1992). Capability and Well-Being. In: Nussbaum, M. \& Sen, A. (eds.) The Quality of Life. Oxford: Oxford University Press.

Shane, S., A (1994). Are champions different from non-champions? Journal of Business Venturing, 9(5), 397-421.

Sipior, J. C. (2005). Departure of the Expert Systems Project Champion. In: Khosrow-Pour, M. (ed.) Encyclopedia of Information Science and Technology. Information Science Reference.

Standish Group. (2009). CHAOS Report 2009: The 10 Laws of CHAOS [Online]. Available: https://www.classes.cs.uchicago.edu/archive/2014/fall/512101/required.reading/Standish.Group.Chaos.2009.pdf [Accessed 30-01-2018].

Swanson, E. B. (1994). Information Systems Innovation among Organizations. Management Science, 40(9), 1069-1092.

Taylor, A., Cocklin, C., Brown, R. \& Wilson-Evered, E. (2011). An investigation of champion-driven leadership processes. Leadership Quarterly, 22(2), 412-433.

Van de Ven, A. H. (1989). Nothing is Quite so Practical as a Good Theory. Academy of Management Review, 14(4), 486-489.

Van Laere, J. \& Aggestam, L. (2016). Understanding Champion Behaviour in a Health-Care Information System Development Project - How Multiple Champions and Champion Behaviours Build a Coherent Whole. European Journal of Information Systems, 25(1), 47-63.

Walsham, G. (1995a). Interpretive Case Studies in IS Research: Nature and Method. European Journal of Information Systems, 4, 74-81.

Walsham, G. (1995b). The Emergence of Interpretivism in IS Research. Information Systems Research, 6(4), 376-394.

Weber, R. (2004). The Rhetoric of Positivism versus Interpretivism: A Personal View. MIS Quarterly, 28(1), iii-xii.

Webster, J. \& Watson, R. T. (2002). Analyzing the Past to Prepare for the Future: Writing a Literature Review. MIS Quarterly, 26(2), xiii-xxiii. 


\section{Appendix A: Data Extraction Form}

\section{1}

\begin{tabular}{|r|r|}
\hline Serial No. & \\
\hline Date Captured & \\
\hline Capturer & \\
\hline
\end{tabular}

Champions of IS Innovations SLR: 1990-2017 Data Capturing Instrument

Source:

\section{A Bibliographic Data}

\section{A_1 Full Reference:}

(Record all bibliographic data such as Authors, Year, Title, Publication Name, Volume Number, Issue, Publisher, Edition, etc. Author/s detail in Section A_3)

\section{A_2 Disciplinary Classification:}

A_3 Type of publication:
Background* (either explicit, or implied from author's departmental location): Rating categories:

- IS=info. systems/info. Mgmt.

- I=innovation

- COMS=communication science

- $P A=$ public admin.

- $P S=$ political science/policy

- $G=g o v e r n a n c e$ or government

- $S S=o t h e r$ social science

- $M=m g m t /$ business school

- $D S=$ development studies

- $S T=$ statistics

- $\boldsymbol{P}=$ practitioner

- $C S=c o m p u t e r$ science/informatics

- $A=$ general academic

- L=law

- LIS=library/info. studies

- $N G O$ (could be non-profit consulting)

- $E B=e$-business

- U=unclear

- $L G=$ linguistics

- $R=$ researcher (non-univ-based)

* So we can see who are researching Champions

\begin{tabular}{|l|l|}
\multicolumn{1}{|c|}{ Surname + Initials (In order) } & Category \\
\hline A_4_1 & \\
A_4_2 & \\
\hline A_4_3 & \\
\hline A_4_4 & \\
\hline A_4_5 & \\
\hline A_4_6 & \\
\hline A_4_7 & \\
\hline A_4_8 & \\
\hline \multicolumn{2}{|c|}{ ]_5 Citation of Paper } \\
How much has this article been cited in the Google Scholar query? \\
Number of Citations: [ $]$ \\
\hline \hline
\end{tabular}




\section{2}

\section{B Research Philosophy}

Is there any explicit statement of research philosophy; particularly related to positivism, interpretive research, critical research, or critical realism? Can some implied research philosophy be ascertained from the approach taken, or from statements about objectivity or subjectivity of certain factors?

(Select $[X]$ ONE Category and indicate $[X]$ if explicitly stated in source)

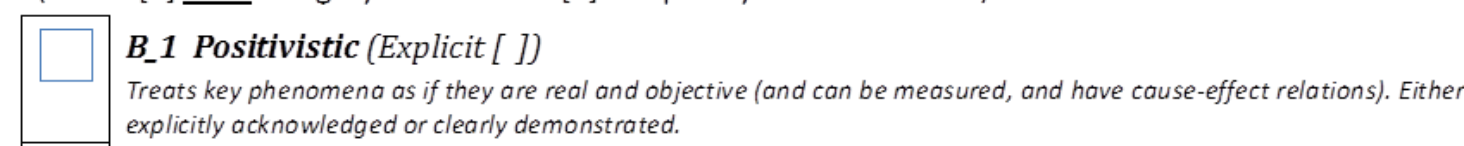

Treats key phenomena as if they are real and objective (and can be measured, and have cause-effect relations). Either B_2 Weak Positivistic (Explicit [ ])

Treat just a few phenomenon as if they are real (or objective) but not clear whether these are seen as objective or what their meaning is or it does not ascribe cause or mixes some positivism with some notion of construction or intersubjectivity of meaning, or relativism.

\section{B_3 Interpretive (Explicit [ ])}

Treat access to reality (given or socially constructed) as subjective and only experienced through social constructions such as language, consciousness and shared meanings (AKA Myers). Either explicitly acknowledged or clearly demonstrated.

\section{B_4 Critical Research (Explicit [ ])}

Focuses on the oppositions, conflicts and contradictions in contemporary society, and seeks to be emancipatory (AKA Myers).

\section{B_5 Critical Realism (Explicit [ ])}

A phenomenon is treated as real (perhaps also with some underlying cause-effect), but as having several different meanings and interpretations that people can put on it.

B_6 Not Explicitly Stated or Implied

\section{Theory Base}

Does the author make explicit use of any particular theory, or model, or framework?

(Select $[X] \underline{\text { ONE})}$
$\square$
C_1 TYPE I. ANALYSIS - Says what is. The theory does not extend beyond analysis and description. No causal relationships among phenomena are specified and no predictions made.

C_2 TYPE II. EXPLANATION) - Says what is, how, why, when, and where. The theory provides explanations but does not aim to predict with any precision. There are no testable propositions.

C_3 TYPE III. PREDICTION - Says what is and what will be. The theory provides predictions and has testable propositions but does not have well-developed justificatory causal explanations.

C_4 TYPE IV. EXPLANATION AND PREDICTION - Says what is, how, why, when, where and what will be. Provides predictions and have both testable propositions and causal explanations.

C_5 TYPE V. DESIGN AND ACTION - Says how to do something. The theory gives explicit prescriptions for constructing an artefact.

If Present, specify: 


\section{Research Approach}

What kind of approach (explicit or implicit) has been used to the relation and ordering of data and theory?

(Select $[\mathrm{X}]$ ONE$)$

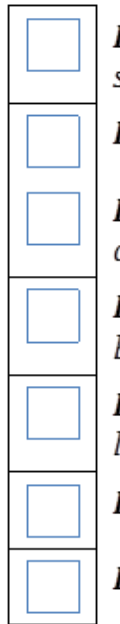

D_1 Quasi-hypothetico-deductive (no explicit recognition, but approximates to setting out some statement and then testing it with data)

D_2 Hypothetico-deductive (does set out some hypothesis/statement for testing)

D_3 Deductive (sets out some theory/concept for testing without making it quite as explicit as a hypothesis)

D_4 Quasi-inductive (no explicit recognition, but approximates to starting with data and building towards some idea or statement)

D_5 Inductive (begins grounded in data and then draws conceptual inferences at the level of at least a mid-level theory model)

D_6 Quasi inductive followed by hypothetico-deductive

\section{D_7 Quasi hypothetico-deductive followed by inductive}

\section{E..Research Strategies / Methodologies}

(Select $[\mathrm{X}]$ as per instructions for each section)

\section{E_1 Methods Section in Paper}

Is there an explicit section on method (could be headed 'research method' or 'methodology' or 'empirical study' or similar)?

\section{E_2 Methods Statement}

Is there an explicit identification of a research method / data sources for the paper?

\section{E_3 Research Strategy}

What was the main research strategy used in the paper?

List ONE that apply best to the research strategy followed in the source.

E_3_1 Speculation/Commentary (Research that derives from thinly supported arguments or opinions with little or no empirical evidence)

E_3_2 Archival Research (Research that is based mainly on the review of existing nonacademic literature)

E_3_3 Literature Analysis (Research that critiques, analyses, and extends existing literature and attempts to build new groundwork)

E_3_4 Case Studies (A single or multiple instances of studying a phenomenon in an organisation over a logical time frame)

E_3_5 Survey Research (Research that uses predefined and structured questionnaires to capture data from individuals.)

E_3_6 Experiment (Research in organizational setting or simulated environment that manipulates and controls the various experimental variables and subjects)

E_3_7 Secondary Data Analysis (A study that utilizes existing organizational and business data, e.g., financial reports, archival data, published statistics)

E_3_8 Content Analysis (A method of analysis in which text is systematically examined by identifying and grouping themes and coding, classifying and developing categories)

E_3_9 Ethnography (Deseribing the culture of an individual or group and understanding a way of life from the narrative point of view.)

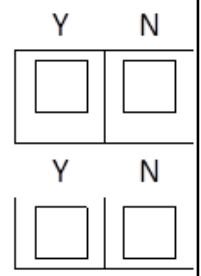


E_3_10 Action Research (The process of actively participating in an organization change situation whilst conducting research)

E_3_11 Field Study (Study of single or multiple and related processes/ phenomena in single or multiple organizations)

\section{E_4 General Methods}

What was the main research method used in the paper?

List ALL that apply. Use Project Experience category where not any explicit research method, just their own experience. Provide an indication of the sample / size [N].

E_4_1 Web site content evaluation/analysis $\mathrm{N}=$ [ ]

E_4_2 Web usage analysis (automatic) $\mathrm{N}=[$ ]

E_4_3 Questionnaire $N=[\quad]$

E_4_4 No statement or indication of how data was gathered

E_4_5 Document analys is

E_4_6 Interviews $\mathrm{N}=[\quad]$

E_4_7 Observations $\mathrm{N}=[\quad]$

E_4_8 Visits (less structured than observations) $\mathrm{N}=[\mathrm{]}$

E_4_9 Project experience (worked on the project itself) - a kind of action research/participantobservation but weaker

E_4_10 Experiments $\mathrm{N}=[\quad]$

E_4_11 Discussion Analysis $N=[\quad]$

E_4_12 DelphiStudy $\mathrm{N}=[\quad]$

\section{E_5 Quantitative/Qualitative Nature of Research Method}

Has the author used a quantitative method or qualitative method, or a combination? Select $[X]$ ONE of the following categories that is the best fit.

E_5_1 Qualitative (e.g. action research, field survey (case study or ethnography))

E_5_2 Quantitative Weak (e.g.scoring a pilot sample of Web sites against criteria)

E_5_3 Quantitative Strong (statistics and significant sample (e.g. a survey or experiment))

E_5_4 Mixed with Quantitative Weak (often quant is rating scales)

E_5_5 Mixed with Quantitative Strong (with Quantitative Strong-type stats)

\section{E_6 Time Profile of Research Method}

Do they use a cross-sectional or longitudinal approach? Time profiling relates to the way data was gathered, not to the background section or to the presentation of data.

Select $[X]$ ONE of the following categories that is the best fit.

E_6_1 Cross-sectional: just related to a single time period (though may give some background of trends)

E_6_2 Trend: main element includes some kind of a history

E_6_3 Longitudinal - uses time as an important factor for study
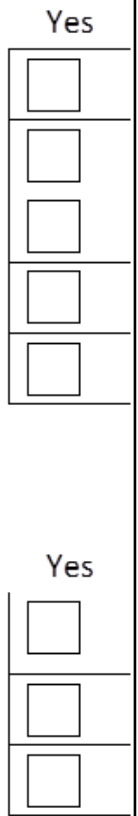


\section{5}

\section{F Content Analysis}

(Select $[\mathrm{X}]$ as per instructions for each section)

\section{F_1 Champion Identification}

Provide a brief description of how the champions were identified for the study. Use the following concepts in the description: Nomination by someone else (e.g. peers, managers, executives, etc.); Self-nomination; Triangulation; Identified by researcher through interviews / observations / document review; Use of a predefined definition; Appointed; Not clear how they were identified.

\section{F_2 Thematic Area/s}

Select [X] ONE or MORE of the following thematic areas which the paper focusses on. The key knowledge contribution must be identified by reviewing the research questions, hypotheses and findings (i.e. what the researcher sets out to analyse).

F_2_1 Champion Origin (an analytic objective of the paper is to explore or explain where champions come from and how they originate)

F_2_2 Competencies \& Identities (an analytic objective of the paper is to explore or explain the characteristics of champions - their skills, attributes, knowledge, worldviews and identities)

F_2_3 Role \& Activities (an analytic objective of the paper is to explore or explain what champions do within organisations or projects and how they do it)

F_2_4 Relationships \& Influence (an analytic objective of the paper is to explore or explain the relational nature of champions - relationships, networks, \& interaction with other stakeholders)

F_2_5 Resource Identification \& Mobilisation (an analytic objective of the paper is to explore or explain how the role and activities of champions in terms of identifying and mobilisation resources)

F_2_6 Impact on Projects / Organisations (an analytic objective of the paper is to explore or explain the impact of champions, positive or negative, in organisations and/or the various phases of projects)

F_2_7 Champion Support / Development (an analytic objective of the paper is to explore or explain how the incidence of champions, their influence and impact, can be optimised)

\section{G General Comments and Observations about Research Quality}




\section{Appendix B: Summary of Extracted Data}

\begin{tabular}{|c|c|c|c|c|c|c|c|c|}
\hline ID & Paper & Citations & $\begin{array}{l}\text { Research } \\
\text { Philosophy }\end{array}$ & $\begin{array}{l}\text { Research } \\
\text { Approach }\end{array}$ & $\begin{array}{l}\text { Research } \\
\text { Strategy }\end{array}$ & Methods & $\begin{array}{l}\text { Qualitative / } \\
\text { Quantitative } \\
\text { Nature }\end{array}$ & $\begin{array}{l}\text { Time } \\
\text { Profile }\end{array}$ \\
\hline 1. & $\begin{array}{l}\text { Howell \& } \\
\text { Higgins } \\
\text { (1990a) }\end{array}$ & 235 & $\begin{array}{l}\text { Weak } \\
\text { Positivistic }\end{array}$ & $\begin{array}{l}\text { Quasi- } \\
\text { Inductive }\end{array}$ & Field Study & In-depth interviews $(\mathrm{N}=25)$ & Qualitative & $\begin{array}{l}\text { Single } \\
\text { Period }\end{array}$ \\
\hline 2. & $\begin{array}{l}\text { Howell \& } \\
\text { Higgins } \\
(1990 b)\end{array}$ & 1112 & Positivistic & $\begin{array}{l}\text { Hypothetic- } \\
\text { Deductive }\end{array}$ & Field Study & $\begin{array}{l}\text { Mixed-methods: } \\
\text { Questionnaires }(\mathrm{N}=50) \text { and } \\
\text { Structured interviews }(\mathrm{N}=156) \text { with } \\
\text { matched pairs of champions and } \\
\text { non-champions }(\mathrm{N}=25)\end{array}$ & $\begin{array}{l}\text { Mixed: Strong } \\
\text { Quantitative }\end{array}$ & $\begin{array}{l}\text { Single } \\
\text { Period }\end{array}$ \\
\hline 3. & $\begin{array}{l}\text { Howell \& } \\
\text { Higgins } \\
\text { (1990c) }\end{array}$ & 66 & Positivistic & $\begin{array}{l}\text { Hypothetic- } \\
\text { Deductive }\end{array}$ & $\begin{array}{l}\text { Content } \\
\text { Analysis }\end{array}$ & $\begin{array}{l}\text { Structured Interviews }(\mathrm{N}=153) ; \\
\text { Matched pairs of champions and } \\
\text { non-champions }(\mathrm{N}=25)\end{array}$ & $\begin{array}{l}\text { Mixed: Strong } \\
\text { Quantitative }\end{array}$ & $\begin{array}{l}\text { Single } \\
\text { Period }\end{array}$ \\
\hline 4. & $\begin{array}{l}\text { Beath } \\
(1991)\end{array}$ & 376 & $\begin{array}{l}\text { Weak } \\
\text { Positivistic }\end{array}$ & $\begin{array}{l}\text { Hypothetic- } \\
\text { Deductive }\end{array}$ & Field Study & $\begin{array}{l}\text { Mixed-methods: } \\
\text { Semi-structured interviews with IT } \\
\text { champions }(\mathrm{N}=15) \text { and managers } \\
\text { (N=27); Follow-up survey }\end{array}$ & $\begin{array}{l}\text { Mixed: Weak } \\
\text { Quantitative }\end{array}$ & $\begin{array}{l}\text { Single } \\
\text { Period }\end{array}$ \\
\hline 5. & $\begin{array}{l}\text { Shane } \\
(1994)\end{array}$ & 111 & Positivistic & $\begin{array}{l}\text { Hypothetic- } \\
\text { Deductive }\end{array}$ & $\begin{array}{l}\text { Survey } \\
\text { Research }\end{array}$ & $\begin{array}{l}\text { Questionnaire: } \mathrm{N}=4405,68 \\
\text { countries, } 43 \text { organisations. } \\
\text { Comparative study: Championing vs. } \\
\text { non-championing behaviour. }\end{array}$ & Quantitative & $\begin{array}{l}\text { Single } \\
\text { Period }\end{array}$ \\
\hline 6. & $\begin{array}{l}\text { Beechler } \\
\text { (1996) }\end{array}$ & 0 & Positivistic & $\begin{array}{l}\text { Hypothetic- } \\
\text { Deductive }\end{array}$ & $\begin{array}{l}\text { Survey } \\
\text { Research }\end{array}$ & $\begin{array}{l}\text { Questionnaire }-N=678 \text { managers in } \\
\text { 8 Japanese firms; }\end{array}$ & Quantitative & $\begin{array}{l}\text { Single } \\
\text { Period }\end{array}$ \\
\hline 7. & $\begin{array}{l}\text { Heng et al } \\
(1999)\end{array}$ & 30 & Interpretive & $\begin{array}{l}\text { Deductive } \\
\text { then } \\
\text { Inductive }\end{array}$ & Field Study & $\begin{array}{l}\text { Unstructured Interviews ( } \mathrm{N}=10 \\
\text { champions) }\end{array}$ & Qualitative & $\begin{array}{l}\text { Single } \\
\text { Period }\end{array}$ \\
\hline 8. & $\begin{array}{l}\text { Howell \& } \\
\text { Shea } \\
(2001)\end{array}$ & 166 & Positivistic & $\begin{array}{l}\text { Hypothetic- } \\
\text { Deductive }\end{array}$ & $\begin{array}{l}\text { Survey } \\
\text { Research }\end{array}$ & $\begin{array}{l}\text { Mixed-methods } \\
\text { Structured interviews with champions } \\
\text { followed by questionnaires }(\mathrm{N}=47) ; \\
\text { Survey of innovation team members } \\
(\mathrm{N}=216) \text {; Follow-up survey }(\mathrm{N}=47) ;\end{array}$ & $\begin{array}{l}\text { Mixed: Strong } \\
\text { Quantitative }\end{array}$ & $\begin{array}{l}\text { Longitu- } \\
\text { dinal }\end{array}$ \\
\hline 9. & \begin{tabular}{|l|} 
Esteves \& \\
Pastor \\
$(2002)$
\end{tabular} & 19 & $\begin{array}{l}\text { Weak } \\
\text { Positivistic }\end{array}$ & $\begin{array}{l}\text { Deductive } \\
\text { then } \\
\text { Inductive }\end{array}$ & $\begin{array}{l}\text { Survey } \\
\text { Research }\end{array}$ & $\begin{array}{l}\text { Questionnaire }(\mathrm{N}=23) \\
\text { Web survey format }\end{array}$ & $\begin{array}{l}\text { Mixed: Weak } \\
\text { Quantitative }\end{array}$ & $\begin{array}{l}\text { Single } \\
\text { Period }\end{array}$ \\
\hline 10. & $\begin{array}{l}\text { Howell \& } \\
\text { Boies } \\
(2004)\end{array}$ & 134 & Positivistic & $\begin{array}{l}\text { Deductive } \\
\text { then } \\
\text { Inductive }\end{array}$ & $\begin{array}{l}\text { Content } \\
\text { Analysis }\end{array}$ & $\begin{array}{l}\text { Structured Interviews }(\mathrm{N}=153) ; 19 \\
\text { Matched pairs of champions and } \\
\text { non-champions. }\end{array}$ & $\begin{array}{l}\text { Mixed: Strong } \\
\text { Quantitative }\end{array}$ & $\begin{array}{l}\text { Single } \\
\text { Period }\end{array}$ \\
\hline 11. & $\begin{array}{l}\text { Gupta et } \\
\text { al (2006) }\end{array}$ & 15 & $\begin{array}{l}\text { Weak } \\
\text { Positivistic }\end{array}$ & $\begin{array}{l}\text { Deductive } \\
\text { then } \\
\text { Inductive }\end{array}$ & $\begin{array}{l}\text { Single Case } \\
\text { Study }\end{array}$ & $\begin{array}{l}\text { Multiple-methods: } \\
\text { Semi-structured interviews }(\mathrm{N}=8) \text {, } \\
\text { secondary data, notes from } \\
\text { observations }\end{array}$ & Qualitative & $\begin{array}{l}\text { Longitu- } \\
\text { dinal }\end{array}$ \\
\hline 12. & $\begin{array}{l}\text { Lefley } \\
(2006)\end{array}$ & 10 & $\begin{array}{l}\text { Weak } \\
\text { Positivistic }\end{array}$ & $\begin{array}{l}\text { Quasi- } \\
\text { Hypothetic- } \\
\text { Deductive }\end{array}$ & $\begin{array}{l}\text { Single Case } \\
\text { Study }\end{array}$ & $\begin{array}{l}\text { Delphi. FAP documentation and } \\
\text { contributions of appraisal team } \\
\text { members, including the champion. }\end{array}$ & $\begin{array}{l}\text { Weak } \\
\text { Quantitative }\end{array}$ & $\begin{array}{l}\text { Single } \\
\text { Period }\end{array}$ \\
\hline 13. & $\begin{array}{l}\text { Dong et al } \\
(2007)\end{array}$ & 8 & Positivistic & $\begin{array}{l}\text { Hypothetic- } \\
\text { Deductive }\end{array}$ & $\begin{array}{l}\text { Survey } \\
\text { Research }\end{array}$ & $\begin{array}{l}\text { Questionnaire ( } \mathrm{N}=138 \text { users), } 5 \\
\text { organisations. }\end{array}$ & Quantitative & $\begin{array}{l}\text { Single } \\
\text { Period }\end{array}$ \\
\hline 14. & $\begin{array}{l}\text { Mullins et } \\
\text { al (2008) }\end{array}$ & 10 & Positivistic & $\begin{array}{l}\text { Hypothetic- } \\
\text { Deductive }\end{array}$ & $\begin{array}{l}\text { Survey } \\
\text { Research }\end{array}$ & $\begin{array}{l}\text { Questionnaire - Originally } \mathrm{N}=169 \\
\text { Follow-up } \mathrm{N}=70\end{array}$ & Quantitative & $\begin{array}{l}\text { Longitu- } \\
\text { dinal }\end{array}$ \\
\hline 15. & \begin{tabular}{|l} 
Kelley \& \\
Lee \\
$(2010)$ \\
\end{tabular} & 14 & Positivistic & $\begin{array}{l}\text { Deductive } \\
\text { then } \\
\text { Inductive }\end{array}$ & $\begin{array}{l}\text { Survey } \\
\text { Research }\end{array}$ & $\begin{array}{l}\text { Questionnaire - N=89 innovation } \\
\text { project champions from } 3 \text { multi- } \\
\text { national Korean Companies }\end{array}$ & Quantitative & $\begin{array}{l}\text { Single } \\
\text { Period }\end{array}$ \\
\hline 16. & $\begin{array}{l}\text { Kamal } \\
(2010)\end{array}$ & 1 & Interpretive & $\begin{array}{l}\text { Quasi- } \\
\text { Hypothetico } \\
\text {-Deductive }\end{array}$ & $\begin{array}{l}\text { Multiple } \\
\text { Case Study }\end{array}$ & $\begin{array}{l}\text { Multiple-methods: } \\
\text { Structured and semi-structured } \\
\text { interviews with champions at } 4 \text { local } \\
\text { government initiatives; Doc analysis. }\end{array}$ & Qualitative & $\begin{array}{l}\text { Single } \\
\text { Period }\end{array}$ \\
\hline 17. & \begin{tabular}{|l|} 
Negoita et \\
al (2012)
\end{tabular} & 0 & $\begin{array}{l}\text { Weak } \\
\text { Positivistic }\end{array}$ & \begin{tabular}{|l|} 
Deductive \\
then \\
Inductive \\
\end{tabular} & $\begin{array}{l}\text { Multiple } \\
\text { Case Study }\end{array}$ & $\begin{array}{l}\text { Semi-structured interviews }(\mathrm{N}=87) ; 5 \\
\text { cases }\end{array}$ & Qualitative & \begin{tabular}{|l|} 
Single \\
Period
\end{tabular} \\
\hline 18. & $\begin{array}{l}\text { Matthews } \\
\text { et al } \\
(2012)\end{array}$ & 0 & Unclear & $\begin{array}{l}\text { Quasi- } \\
\text { Inductive }\end{array}$ & $\begin{array}{l}\text { Single Case } \\
\text { Study }\end{array}$ & $\begin{array}{l}\text { Semi-structured interviews with } \\
\text { design champions; } 2 \text { participants }\end{array}$ & Qualitative & $\begin{array}{l}\text { Longitu- } \\
\text { dinal }\end{array}$ \\
\hline 19. & $\begin{array}{l}\text { Klerkx \& } \\
\text { Aarts } \\
(2013)\end{array}$ & 4 & $\begin{array}{l}\text { Weak } \\
\text { Positivistic }\end{array}$ & $\begin{array}{l}\text { Deductive } \\
\text { then } \\
\text { Inductive }\end{array}$ & $\begin{array}{l}\text { Multiple } \\
\text { Case Study }\end{array}$ & $\begin{array}{l}\text { Multiple-methods: } \\
\text { Document analysis }(\mathrm{N}=1) \text {; Semi- } \\
\text { structured interviews }(\mathrm{N}=78) ; \\
\text { Observations }(\mathrm{N}=10) ; 3 \text { cases }\end{array}$ & Qualitative & \begin{tabular}{|l|} 
Trend: \\
Historic \\
element
\end{tabular} \\
\hline 20. & $\begin{array}{l}\text { Andersen } \\
\text { \& Mørch } \\
\text { (2016) }\end{array}$ & 0 & $\begin{array}{l}\text { Weak } \\
\text { Positivistic }\end{array}$ & $\begin{array}{l}\text { Deductive } \\
\text { then } \\
\text { Inductive }\end{array}$ & $\begin{array}{l}\text { Single Case } \\
\text { Study }\end{array}$ & $\begin{array}{l}\text { Mixed-methods: } \\
\text { SNA based on website content; } \\
\text { Discussion analysis (topics: } 19747 \text {; } \\
\text { participants: } 269280 \text { ). }\end{array}$ & $\begin{array}{l}\text { Mixed: Weak } \\
\text { Quantitative }\end{array}$ & $\begin{array}{l}\text { Single } \\
\text { Period }\end{array}$ \\
\hline
\end{tabular}




\begin{tabular}{|l|l|l|l|l|l|l|l|l|}
\hline ID & Paper & Citations & $\begin{array}{l}\text { Research } \\
\text { Philosophy }\end{array}$ & $\begin{array}{l}\text { Research } \\
\text { Approach }\end{array}$ & $\begin{array}{l}\text { Research } \\
\text { Strategy }\end{array}$ & $\begin{array}{l}\text { Qualitative / } \\
\text { Quantitative } \\
\text { Nature }\end{array}$ & $\begin{array}{l}\text { Time } \\
\text { Profile }\end{array}$ \\
\hline $\begin{array}{l}\text { 21. } \\
\text { Lefley et } \\
\text { al (2016) }\end{array}$ & 0 & Positivistic & $\begin{array}{l}\text { Hypothetic- } \\
\text { Seductive }\end{array}$ & $\begin{array}{l}\text { Survey } \\
\text { Research }\end{array}$ & $\begin{array}{l}\text { Questionnaire (N=152); 81 Czech } \\
\text { Republic + 71 UK. }\end{array}$ & Quantitative & $\begin{array}{l}\text { Single } \\
\text { Period }\end{array}$ \\
\hline $\begin{array}{l}\text { 22. } \\
\text { Van Laere } \\
\text { \& }\end{array}$ & 0 & $\begin{array}{l}\text { Weak } \\
\text { Aggestam } \\
\text { Positivistic }\end{array}$ & Inductive & $\begin{array}{l}\text { Single Case } \\
\text { Study }\end{array}$ & $\begin{array}{l}\text { Multiple-methods: } \\
\text { Exploratory interview (N=1); } \\
\text { Participant observations (N>100) }\end{array}$ & Qualitative & $\begin{array}{l}\text { Trend: } \\
\text { Historic } \\
\text { element }\end{array}$ \\
\hline
\end{tabular}




\begin{abstract}
About the Authors
Jaco Renken is a Lecturer in Information Systems at the University of Manchester, UK. Current research is focused on: i) Champions and leaders and their role in ICT-enabled socio-economic development; ii) The implications of data-intensive development, particularly new forms of data such and big and open data. Past positions were held at the University of Stellenbosch, South Africa, and the University of Botswana in Gaborone, Botswana. The experience from living and working in developing countries is now brought to bear on his ICT4D-focussed research as part of the Manchester Global Development Institute.

Richard Heeks is Chair in Development Informatics at the Global Development Institute, University of Manchester, UK; and Director of the Centre for Development Informatics. He has been consulting and researching on informatics and development for more than 30 years. His research interests are dataintensive development, e-resilience and e-sustainability, digital development, and the digital economy in developing countries.
\end{abstract}

Copyright $(2018$ by the Association for Information Systems. Permission to make digital or hard copies of all or part of this work for personal or classroom use is granted without fee provided that copies are not made or distributed for profit or commercial advantage and that copies bear this notice and full citation on the first page. Copyright for components of this work owned by others than the Association for Information Systems must be honored. Abstracting with credit is permitted. To copy otherwise, to republish, to post on servers, or to redistribute to lists requires prior specific permission and/or fee. Request permission to publish from: AIS Administrative Office, P.O. Box 2712 Atlanta, GA, 30301-2712 Attn: Reprints or via e-mail from publications@aisnet.org. 